\title{
Improving noble gas based paleoclimate reconstruction and groundwater dating using ${ }^{20} \mathrm{Ne} /{ }^{22} \mathrm{Ne}$ ratios
}

\author{
Frank Peeters, ${ }^{1} *$ Urs Beyerle, ${ }^{2}$ Werner Aeschbach-Hertig, ${ }^{1}$ Johannes Holocher, ${ }^{1}$ Matthias S. Brennwald, ${ }^{1}$ and \\ ROLF KIPFER ${ }^{1,3}$ \\ ${ }^{1}$ Environmental Isotopes Group, Dept. of Water Resources and Drinking Water, Swiss Federal Institute of Environmental Science and \\ Technology (EAWAG), P.O. 611, Überlandstrasse 133, CH-8600 Dübendorf, Switzerland \\ ${ }^{2}$ Climate and Environmental Physics, Physics Institute, University of Bern, Sidlerstrasse 5, CH-3012 Bern, Switzerland \\ ${ }^{3}$ Isotope Geology, Dept. of Earth Sciences, Swiss Federal Institute of Science and Technology (ETH), NO C61, CH-8092 Zurich, Switzerland
}

\begin{abstract}
The interpretation of noble gas concentrations in groundwater with respect to recharge temperature and fractionated excess gas leads to different results on paleo-climatic conditions and on residence times depending on the choice of the gas partitioning model. Two fractionation models for the gas excess are in use, one assuming partial re-equilibration of groundwater supersaturated by excess air (PR-model, Stute et al., 1995), the other assuming closed-system equilibration of groundwater with entrapped air (CE-model, Aeschbach-Hertig et al., 2000). In the example of the Continental Terminal aquifers in Niger, PR- and CE- model are both consistent with the data on elemental noble gas concentrations ( $\mathrm{Ne}, \mathrm{Ar}, \mathrm{Kr}$, and $\mathrm{Xe}$ ). Only by including the isotope ratio ${ }^{20} \mathrm{Ne} /{ }^{22} \mathrm{Ne}$ it can be demonstrated that the PR-model has to be rejected and the CE-model should be applied to the data. In dating applications ${ }^{3} \mathrm{He}$ of atmospheric origin $\left({ }^{3} \mathrm{He}_{\mathrm{atm}}\right)$ required to calculate ${ }^{3} \mathrm{H}-{ }^{3} \mathrm{He}$ water ages is commonly estimated from the $\mathrm{Ne}$ excess presuming that gas excess is unfractionated air (UA-model). Including in addition to the $\mathrm{Ne}$ concentration the ${ }^{20} \mathrm{Ne} /{ }^{22} \mathrm{Ne}$ ratio and the concentration of Ar enables a rigorous distinction between PR-, CE- and UA-model and a reliable determination of ${ }^{3} \mathrm{He}_{\mathrm{atm}}$ and of ${ }^{3} \mathrm{H}-{ }^{3} \mathrm{He}$ water ages.
\end{abstract}

\section{INTRODUCTION}

Noble gas concentrations in groundwater have been employed to provide information on paleotemperatures (e.g., Aeschbach-Hertig et al., 2000; Andrews and Lee, 1979; Beyerle et al., 1998; Mazor, 1972; Stute et al., 1995; Weyhenmeyer et al., 2000) and on residence times in aquifers $\left({ }^{3} \mathrm{H}-{ }^{3} \mathrm{He}\right.$ dating e.g., Schlosser et al., 1988; Schlosser et al., 1989; Tolstikhin and Kamenskiy, 1969; ${ }^{4} \mathrm{He}$ dating e.g., Andrews and Lee, 1979; Solomon, 2000). In addition to applications in paleo-climate and dating studies, noble gases can serve as excellent tools to study gas exchange between the atmosphere and groundwater because noble gases are not affected by biogeochemical transformations. The interpretation of noble gas concentrations in groundwater has been improved in the last years and rigorous least squares methods are now available (Aeschbach-Hertig et al., 1999; Ballentine and Hall, 1999) which allow the estimation of e.g., recharge temperature by considering the noble gases $\mathrm{Ne}, \mathrm{Ar}, \mathrm{Kr}$, and $\mathrm{Xe}$ simultaneously.

In most aquifers noble gas concentrations are higher than the concentrations expected at atmospheric solubility equilibrium. This gas excess, commonly called "excess air" (Heaton and Vogel, 1981), must be considered in the calculation of recharge temperature (Stute and Schlosser, 1993) and in the calculation of tritiogenic ${ }^{3} \mathrm{He}$ for dating purposes (Schlosser et al., 1989). The name "excess air" however is misleading because in many aquifers (e.g., Aeschbach-Hertig et al., 2000; Stute et al., 1995) the gas excess does not have the same composition as atmospheric air but the heavier noble gases are enriched compared

* Author to whom correspondence should be addressed (peeters@eawag.ch). to the lighter ones. In several aquifers the amount and composition of the gas excess varies systematically over time and might provide additional information on past climatic conditions related to changes in recharge dynamics (AeschbachHertig et al., 2001; Stute and Talma, 1998, Beyerle et al., in press).

Although gas excess appears to be very common in groundwaters its formation is still not well understood in detail. Two different simplified models describing the formation of excess air and its fractionation (Aeschbach-Hertig et al., 2000; Stute et al., 1995) have been employed to account for the excess of noble gases in paleo-climatic studies and in ${ }^{3} \mathrm{H}-{ }^{3} \mathrm{He}$ dating applications. The two gas exchange models differ in their assumptions on how excess air is formed and on the mechanisms responsible for fractionation.

Because the choice of the gas exchange model affects the results on paleotemperatures and on ${ }^{3} \mathrm{H}-{ }^{3} \mathrm{He}$ water ages, it is necessary to decide on the basis of the available data which of the two models should be applied. However, in most groundwaters the number of elemental noble gas concentrations which can be employed in the inverse fitting procedure to simultaneously estimate recharge temperature, gas excess and its fractionation is limited to four, namely $\mathrm{Ne}, \mathrm{Ar}, \mathrm{Kr}$ and $\mathrm{Xe}$. Unfortunately $\mathrm{He}$, which is the most sensitive of all noble gases to the choice of the gas exchange model, usually cannot be included in the fitting procedure because it has significant additional non-atmospheric sources which cannot be quantified independently.

In this study we demonstrate that the empirical constraints on the gas exchange models can be improved significantly by considering the concentrations of noble gas isotopes and isotope ratios in addition to the commonly used elemental con- 
Table 1a. Partial pressure in the atmosphere, equilibirum concentration $C^{*}$ and molecular diffusivities $D$ of noble gases and their isotopes at different temperatures. Equilibrium concentrations are given for freshwater with $S=0 \%$ at $P=1 \mathrm{~atm}$ of moist air. $C^{*}$ are calculated from the solubilities for ${ }^{3} \mathrm{He},{ }^{4} \mathrm{He}, \mathrm{Ne}$, Ar, and $\mathrm{Kr}$ (Benson and Krause, 1980; Weiss, 1970; Weiss, 1971; Weiss and Kyser, 1978), and the solubilities for Xe (Clever, 1979) using the correction for moist air (Aeschbach-Hertig et al., 1999). $C^{*}$ of ${ }^{22} \mathrm{Ne}$ and ${ }^{36} \mathrm{Ar}$ are calculated from the equilibirum concentration of $\mathrm{Ne}$ and $\mathrm{Ar}$ using the fractionation factors given by Beyerle et al. (2000a). Solubilities of ${ }^{20} \mathrm{Ne}$ and ${ }^{40} \mathrm{Ar}$ are assumed to correspond to the solubilities of $\mathrm{Ne}$ and Ar, respectively. Volume fractions in dry air are taken from Ozima and Podosek (1983) and molecular diffusivities were calculated from the empirical relations of Jähne et al. (1987). Diffusivities of $\mathrm{Ar},{ }^{36} \mathrm{Ar},{ }^{40} \mathrm{Ar},{ }^{22} \mathrm{Ne}$ and ${ }^{3} \mathrm{He}$ were calculated from the other noble gas diffusivites assuming that the $D$ is inversely proportional to the square root of the atomic mass.

\begin{tabular}{|c|c|c|c|c|c|c|c|c|c|}
\hline & & $C^{*}$ at $5^{\circ} \mathrm{C}$ & $C^{*}$ at $10^{\circ} \mathrm{C}$ & $C^{*}$ at $20^{\circ} \mathrm{C}$ & $C^{*}$ at $30^{\circ} \mathrm{C}$ & $D$ at $5^{\circ} \mathrm{C}$ & $D$ at $10^{\circ} \mathrm{C}$ & $D$ at $20^{\circ} \mathrm{C}$ & $D$ at $30^{\circ} \mathrm{C}$ \\
\hline & volume fraction & \multicolumn{4}{|c|}{$\left(\mathrm{cm}^{3}\right.$ STP g $\left.{ }^{-1}\right)$} & \multicolumn{4}{|c|}{$\left(10^{-9} \mathrm{~m}^{2} \mathrm{~s}^{-1}\right)$} \\
\hline $\mathrm{He},{ }^{4} \mathrm{He}$ & $5.24 \cdot 10^{-6}$ & $4.760 \cdot 10^{-8}$ & $4.645 \cdot 10^{-8}$ & $4.477 \cdot 10^{-8}$ & $4.357 \cdot 10^{-8}$ & 5.195 & 5.680 & 6.730 & 7.884 \\
\hline $\mathrm{Ne}$ & $1.818 \cdot 10^{-5}$ & $2.123 \cdot 10^{-7}$ & $2.017 \cdot 10^{-7}$ & $1.851 \cdot 10^{-7}$ & $1.724 \cdot 10^{-7}$ & 2.627 & 2.942 & 3.648 & 4.459 \\
\hline $\mathrm{Ar}$ & $9.34 \cdot 10^{-3}$ & $4.359 \cdot 10^{-4}$ & $3.861 \cdot 10^{-4}$ & $3.119 \cdot 10^{-4}$ & $2.599 \cdot 10^{-4}$ & 1.646 & 1.870 & 2.381 & 2.984 \\
\hline $\mathrm{Kr}$ & $1.14 \cdot 10^{-6}$ & $1.057 \cdot 10^{-7}$ & $9.103 \cdot 10^{-8}$ & $6.967 \cdot 10^{-8}$ & $5.523 \cdot 10^{-8}$ & 1.029 & 1.200 & 1.608 & 2.114 \\
\hline $\mathrm{Xe}$ & $8.7 \cdot 10^{-8}$ & $1.581 \cdot 10^{-8}$ & $1.318 \cdot 10^{-8}$ & $9.517 \cdot 10^{-9}$ & $7.178 \cdot 10^{-9}$ & 0.788 & 0.929 & 1.271 & 1.702 \\
\hline${ }^{20} \mathrm{Ne}$ & $1.645 \cdot 10^{-5}$ & $1.921 \cdot 10^{-7}$ & $1.826 \cdot 10^{-7}$ & $1.675 \cdot 10^{-7}$ & $1.560 \cdot 10^{-7}$ & 2.627 & 2.942 & 3.648 & 4.459 \\
\hline${ }^{40} \mathrm{Ar}$ & $9.303 \cdot 10^{-3}$ & $4.342 \cdot 10^{-4}$ & $3.846 \cdot 10^{-4}$ & $3.107 \cdot 10^{-4}$ & $2.589 \cdot 10^{-4}$ & 1.646 & 1.870 & 2.381 & 2.984 \\
\hline
\end{tabular}

centrations of noble gases. In particular, including Ne isotopes proves to be very useful in distinguishing between different gas exchange models. The interpretation of data on noble gas isotopes with respect to excess air and its fractionation is demonstrated using noble gas data from the Continental Terminal aquifers in Niger (Beyerle et al., 2002).

\section{THEORY AND METHODS}

\subsection{Gas Exchange Models and their Sensitivity to Noble Gas Concentrations}

The most simple explanation for the excess of dissolved atmospheric gases in groundwater is that initially the gasconcentrations in the groundwater are in equilibrium with the atmosphere and that gas bubbles with atmospheric gas composition are trapped and completely dissolved, introducing excess gases in the same ratio as in the atmosphere into the water. This assumption, which we refer to as the unfractionated excess air (UA) model, has been used in most paleoclimatic studies based on noble gas concentrations from groundwaters (e.g., Andrews and Lee, 1979; Heaton and Vogel, 1981; Stute and Schlosser, 1993). However, recent studies have shown that the gas excess can be fractionated compared to the atmospheric gas composition. Two models have been developed to describe this situation, the partial re-equilibration model (PR-model) by Stute et al. (1995), and the closed system equilibration model (CEmodel) by Aeschbach-Hertig et al. (2000). In the following we briefly describe the underlying model assumptions and their consequences on the noble gas concentrations and fractionation.

The PR-model assumes that initially the trapped air bubbles dissolve completely, as in the UA-model. The initial excess air suggested by the model can correspond to gas concentrations which are several times larger than the atmospheric equilibrium concentrations (e.g., Stute et al., 1995). This also implies that e.g., initial oxygen levels in groundwater might be significantly above atmospheric equilibrium which would have consequences on groundwater ecology and water quality. According to the model, the gas excess in the water leads to a diffusion of gas out of the water across the groundwater table and diffusion is assumed to be at molecular level. Because the molecular diffusivities of the noble gases decrease with atomic mass, the light noble gases are lost much faster than heavier ones (Table 1a). This process increases the ratio of heavy to light noble gas concentrations in the water and thus leads to the typical fractionation pattern of the noble gas composition in the gas excess of groundwater. Some of the fractionated gas excess remains in the groundwater because infiltration and groundwater flow eventually move the water away from the air/water interface, preventing further gas loss by diffusion.

Conceptually, the model assumes a partial re-equilibration of water which was initially over-saturated by air with atmospheric composition. The effect of the PR-model on the dissolved gas concentration $i$ can be described by (AeschbachHertig et al., 1999, reformulation of the model by Stute et al., 1995):

$$
\begin{aligned}
C_{i}\left(T, S, P, A_{p r}, F_{p r}\right)=C^{*}{ }_{i}(T, S, P)+A_{p r} \cdot & z_{i} \cdot \\
& \exp \left(-F_{p r} \frac{D_{i}}{D_{N e}}\right)
\end{aligned}
$$

where $C^{*}{ }_{i}$ is the equilibrium concentration between atmosphere and water at atmospheric pressure $P$, water temperature $T$ and salinity $S$ during air water partitioning. The equilibrium concentration is determined using the Henry coefficient of the gas considered. Details on the calculation of $C^{*}{ }_{i}$ are given in Aeschbach-Hertig et al. (1999). $z_{i}$ is the atmospheric volume fraction of noble gas $i$ in dry air, $D_{i}$ is its molecular diffusivity, and $D_{N e}$ is the molecular diffusivity of Ne. $A_{p r}$ is the amount of initial excess air and $F_{p r}$ is the fractionation parameter which must be positve. $F_{p r}$ can be interpreted as being proportional to the time during which the initial gas excess is lost to the atmosphere. In most cases $T, A_{p r}$ and $F_{p r}$ are treated as fit parameters whereas $P$ and $S$ are commonly prescribed as present day atmospheric pressure and present day salinity of the infiltrating water (for meteoric water $\mathrm{S} \approx 0$ ). Note, that for $F_{p r}=$ 0 (1) reduces to the UA-model.

As in the UA- and PR-models, Aeschbach-Hertig et al. (2000) assume that the gas-concentrations in the recharging water initially are in equilibrium with the atmosphere at atmospheric pressure and soil temperature and that bubbles of at- 
Table 1b. Ratios of partial pressure in the atmosphere, of equilibirum concentration and of molecular diffusivity at different temperatures for selected noble gas istotopes and $\mathrm{Ar}$ and $\mathrm{Ne}$.

\begin{tabular}{|c|c|c|c|c|c|c|c|c|c|}
\hline & volume fraction & $\begin{array}{c}C^{*}{ }_{A} / C^{*}{ }_{B} \text { at } \\
5^{\circ} \mathrm{C}(-) \\
\end{array}$ & $\begin{array}{c}C^{*}{ }_{A} / C^{*}{ }_{B} \text { at } \\
10^{\circ} \mathrm{C}(-) \\
\end{array}$ & $\begin{array}{l}C^{*}{ }_{A} / C^{*}{ }_{B} \text { at } \\
20^{\circ} \mathrm{C}(-) \\
\end{array}$ & $\begin{array}{l}C^{*}{ }_{A} / C^{*}{ }_{B} \text { at } \\
30^{\circ} \mathrm{C}(-) \\
\end{array}$ & $\begin{array}{l}D_{A} / D_{B} \text { at } \\
5^{\circ} \mathrm{C}(-)\end{array}$ & $\begin{array}{l}D_{A} / D_{B} \text { at } \\
10^{\circ} \mathrm{C}(-)\end{array}$ & $\begin{array}{l}D_{A} / D_{B} \text { at } \\
20^{\circ} \mathrm{C}(-)\end{array}$ & $\begin{array}{l}D_{A} / D_{B} \text { at } \\
30^{\circ} \mathrm{C}(-) \\
\end{array}$ \\
\hline $1 \mathrm{c}$ & $1.384 \cdot 10^{-6}$ & $1.3596 \cdot 10^{-6}$ & $1.3602 \cdot 10^{-6}$ & $1.3614 \cdot 10^{-6}$ & $1.3625 \cdot 10^{-6}$ & 1.155 & 1.155 & 1.155 & 1.155 \\
\hline${ }^{20} \mathrm{Ne} /{ }^{22} \mathrm{Ne}$ & 9.8000 & 9.7804 & 9.7804 & 9.7804 & 9.7804 & 1.049 & 1.049 & 1.049 & 1.049 \\
\hline${ }^{36} \mathrm{Ar} /{ }^{40} \mathrm{Ar}$ & $3.384 \cdot 10^{-3}$ & $3.380 \cdot 10^{-3}$ & $3.380 \cdot 10^{-3}$ & $3.380 \cdot 10^{-3}$ & $3.380 \cdot 10^{-3}$ & 1.054 & 1.054 & 1.054 & 1.054 \\
\hline $\mathrm{Ne} / \mathrm{Ar}$ & $1.946 \cdot 10^{-3}$ & $4.870 \cdot 10^{-4}$ & $5.225 \cdot 10^{-4}$ & $5.935 \cdot 10^{-4}$ & $6.633 \cdot 10^{-4}$ & 1.596 & 1.573 & 1.532 & 1.494 \\
\hline
\end{tabular}

mospheric air are trapped. However, instead of assuming complete dissolution of bubbles, they postulate that a reservoir of entrapped gas remains in the quasi-saturated zone. Water and entrapped gas are thought to form a closed system which equilibrates at hydrostatic pressure and surrounding soil temperature. This process changes the concentrations and the relative composition of noble gases in the groundwater and in the entrapped gas. The gas concentrations in the water resulting from the closed-system equilibration can be described by (CEmodel, Aeschbach-Hertig et al., 2000):

$$
C_{i}(T, S, P, A, F)=C_{i}^{*}(T, S, P)+\frac{\left(1-F_{c e}\right) A_{c c} z_{i}}{1+F_{c e} A_{c e} z_{i} / C^{*}{ }_{i}(T, S, P)}
$$

The parameter $A_{c e}$ describes the initial STP-volume of dry air in the trapped gas per unit mass of water and the parameter $F_{c e}$ describes the reduction of the volume of entrapped air $A_{c e}$ due to partial dissolution and compression of the gas volume. The value of $F_{c e}$ is restricted to the interval between 0 and 1 , where $F_{c e}=0$ implies unfractionated excess air and $F_{c e}=1$ implies no gas excess. As in the PR-model, temperature $T$ and the parameters determining the gas excess and its fractionation, $A_{c e}$ and $F_{c e}$, are usually treated as fit parameters whereas $P$ and $S$ at recharge are prescribed.

The UA-model, assuming complete dissolution of the entrapped air without subsequent gas loss, corresponds to the limiting case of the PR- and CE-models with no fractionation $\left(F_{p r}=F_{c e}=0\right)$. In this case, $A_{p r}$ in the PR-model and $A_{c e}$ in the CE-model assume the same value and the predicted recharge temperature $T$ is the same in both models. However, if the gas excess is fractionated compared to the atmospheric gas composition, predictions based on the PR- and the CE-model differ significantly.

According to the PR-model fractionation of the gas excess is solely due to differences in the molecular diffusivities between the gases:

$$
\frac{\Delta C_{A}}{\Delta C_{B}}=\frac{z_{A}}{z_{B}} \cdot \exp \left(-F_{p r} \frac{D_{A}-D_{B}}{D_{N e}}\right) \text { for } A_{p r} \neq 0
$$

where $\Delta C=\left(C-C^{*}\right)$ is the gas excess, and the ratio of the excess of gas A to the excess of gas $\mathrm{B}$ is a measure of fractionation. Excess gas only exists if $A_{p r} \neq 0$. Choosing A and $\mathrm{B}$ such that $D_{A}>D_{B}$, the ratio of the gas excess $\Delta C_{A} / \Delta C_{B}$ tends to 0 for $F_{p r} \rightarrow \infty$. If $F_{p r} \rightarrow 0$ excess air has atmospheric composition $\left(\Delta C_{A} / \Delta C_{B}=z_{A} / z_{B}\right)$. The ratio of the dissolved gas concentrations $C_{A} / C_{B}$ can range between $0\left(A_{p r} \rightarrow \infty\right.$ and $F_{p r} \rightarrow$ $\left.\ln \left\{A_{p r} / C_{A}{ }^{*}\right\} \cdot D_{N e} / D_{A}\right)$, the maximum of $z_{A} / z_{B}\left(A_{p r} \rightarrow \infty\right.$ and $F_{p r}$ $=0)$, and $C_{A}{ }^{*} / C_{B}{ }^{*}\left(A_{p r}=0\right.$ or $F_{p r} \rightarrow \infty$; i.e., no gas excess exists). Note that the limits given above are those for model Eqn. 1 but that the underlying physical concept breaks down at very large values of $A_{p r}$ because the initial ratio of air to water volume becomes unreasonably large. Figure 1a demonstrates how the concentration ratio of ${ }^{20} \mathrm{Ne}$ to ${ }^{22} \mathrm{Ne}, C_{20 \mathrm{Ne}} / C_{22 \mathrm{Ne}}$, depends on excess air and fractionation in the PR-model, i.e., on the parameters $A_{p r}$ and $F_{p r}$. At given $A_{p r}, C_{20 \mathrm{Ne}} / C_{22 \mathrm{Ne}}$ decreases with increasing $F_{p r}$ until a minimum concentration ratio is reached and then increases again to finally approach atmospheric equilibrium at large $F_{p r}$. The larger the amount of initial excess air $A_{p r}$ the lower the minimum of $C_{20 \mathrm{Ne}} / C_{22 \mathrm{Ne}}$.

In the CE-model, fractionation does not depend on molecular diffusivities but on the differences in the Henry coefficients between the gas species and the ratio of water volume to volume of entrapped air:

$$
\begin{aligned}
\frac{\Delta C_{A}}{\Delta C_{B}}=\frac{z_{A}}{z_{B}} \cdot \frac{C_{A}^{*}}{C_{B}^{*}} \cdot \frac{C_{B}^{*}+F_{c e} A_{c e} z_{B}}{C^{*}{ }_{A}+F_{c e} A_{c e} z_{A}} \text { for } F_{c e} & \neq 1 \\
& \text { and } A_{c e} \neq 0
\end{aligned}
$$

where the dependence on the Henry coefficients is implicitly contained in the equilibrium concentrations $C_{A}{ }^{*}$ and $C_{B}{ }^{*}$ (Aeschbach-Hertig et al., 1999) and the dependence on water volume and volume of entrapped air is contained in the parameters $F_{c e}$ and $A_{c e}$. Eqn. 4 assumes $F_{c e} \neq 1$ and $A_{c e} \neq 0$ because only then excess gas exists. $\Delta C_{A} / \Delta C_{B}$ ranges between $C_{A}{ }^{*} / C_{B}{ }^{*}$ $\left(A_{c e} \rightarrow \infty, F_{c e} \neq 0\right)$ and the ratio in unfractionated air $z_{A} / z_{B}\left(F_{c e}\right.$ $=0$ ). In contrast to the PR-model, the ratio of the dissolved gas concentrations $C_{A} / C_{B}$ in the CE-model cannot approach 0 but must range between $C_{A}{ }^{*} / C_{B}{ }^{*}\left(F_{c e}=1\right.$ or $\left.A_{c e}=0\right)$ and $z_{A} / z_{B}$ $\left(F_{c e} \rightarrow 0, A_{c e} \rightarrow \infty\right.$ and $\left.F_{c e} \cdot A_{c e} \rightarrow 0\right)$. Note that the physical concept underlying the CE-model breaks down for $A_{c e} \rightarrow \infty$. Fig. 1b shows how the concentration ratio $C_{2 O N e} / C_{22 N e}$ varies with $A_{c e}$ and $F_{c e}$. At given $A_{c e}$, the concentration ratio $C_{20 N e}$ $C_{22 \mathrm{Ne}}$ decreases monotonically with the parameter $F_{c e}$ and reaches $C_{A}{ }^{*} / C_{B}{ }^{*}$ at $F_{c e}=1$. The concentration ratio at $F_{c e}=0$ increases with increasing $A_{c e}$ but cannot exceed $z_{2 O N e} / z_{22 \mathrm{Ne}}$.

Eqn. 3 and 4 imply that noble gases with Henry coefficients of similar magnitude but with very different molecular diffusivies should react much more sensitive to fractionation according to the PR-model than the CE-model and could be used to test which model is applicable. Because of the very large molecular diffusivity of He (Table 1), the model choice especially affects the predicted ratio between $\mathrm{He}$ and the heavier noble gases $(\mathrm{Ne}, \mathrm{Ar}, \mathrm{Kr}, \mathrm{Xe})$. This is particularly important in ${ }^{3} \mathrm{H}-{ }^{3} \mathrm{He}$ groundwater dating, where the ${ }^{3} \mathrm{He}$ contribution of atmospheric origin, ${ }^{3} \mathrm{He}_{\text {atm }}$, has to be known. In case of fractionated excess air ${ }^{3} \mathrm{He}_{\mathrm{atm}}$ and consequently the ${ }^{3} \mathrm{H}-{ }^{3} \mathrm{He}$ water age derived depend strongly on the gas exchange model em- 

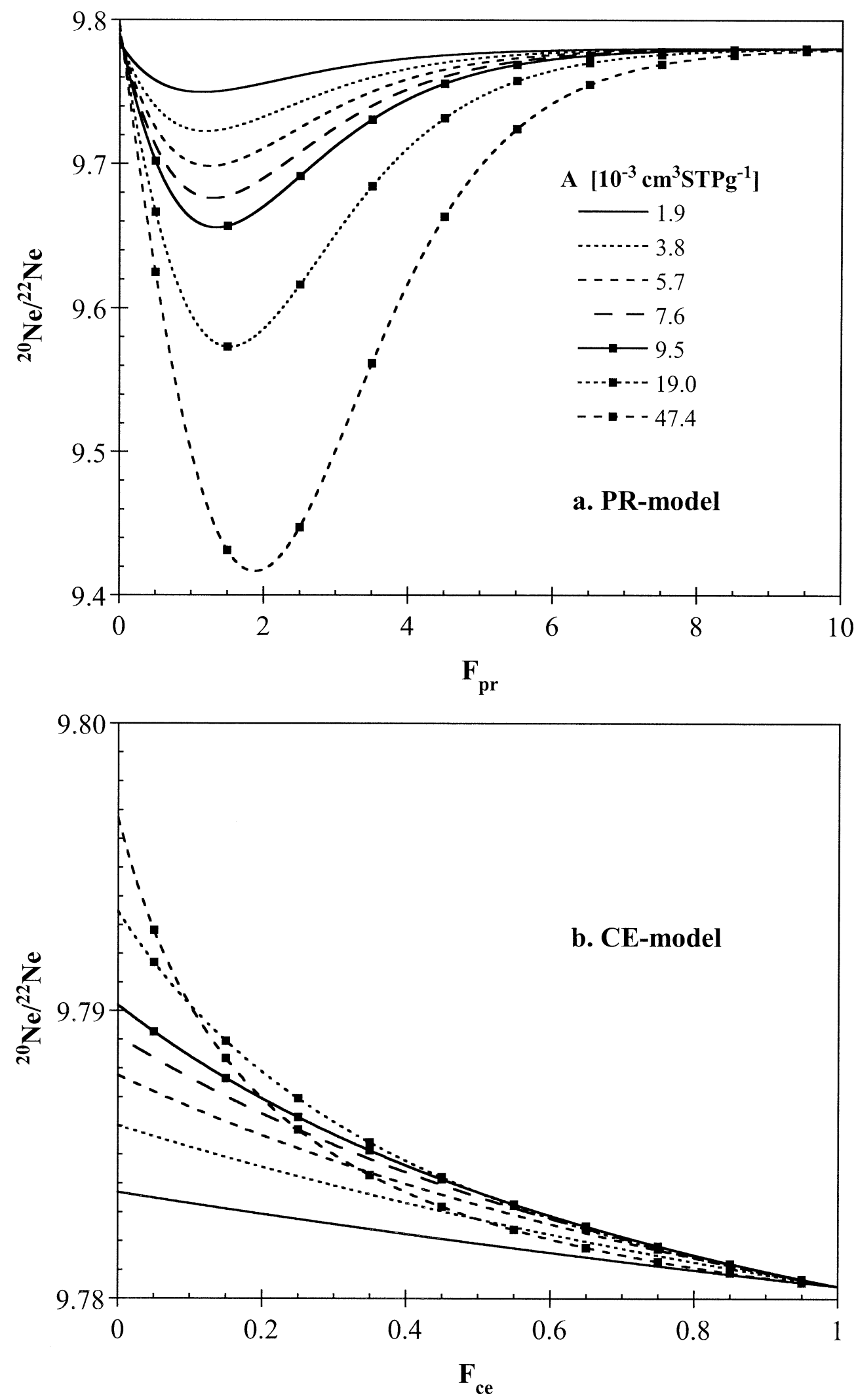

Fig. $1 .{ }^{20} \mathrm{Ne} / 22 \mathrm{Ne}$ ratio as function of $A_{p r}$ and $F_{p r}$ for the PR-model (a) and $A_{c e}$ and $F_{c e}$ for the CE-model (b). Each line represents the variation of ${ }^{20} \mathrm{Ne} /{ }^{22} \mathrm{Ne}$ ratio with $F_{p r}\left(\right.$ a) and $F_{c e}$ (b) at a fixed value of $A$, i.e., a fixed $A_{p r}$ and $A_{c e}$, respectively. Conditions at recharge are assumed to be $T=30^{\circ} \mathrm{C}, p=1 \mathrm{~atm}$ and $S=0$. Note that the CE-model only allows $F_{c e}$ to range between 0 and 1 . 
ployed. The presence of terrigenic and radiogenic/tritiogenic $\mathrm{He}$ sources prevents the use of He to distinguish between the PR- and the CE-model.

Isotopes of the the same noble gas have very similar Henry coefficients but can have significantly different molecular diffusivities (Table 1b). That is especially the case for the light noble gas isotopes ${ }^{3} \mathrm{He}-{ }^{4} \mathrm{He},{ }^{20} \mathrm{Ne}-{ }^{22} \mathrm{Ne}$, and ${ }^{36} \mathrm{Ar}-{ }^{40} \mathrm{Ar}$. According to the above discussion, the isotopic ratios ${ }^{3} \mathrm{He} /{ }^{4} \mathrm{He}$, ${ }^{20} \mathrm{Ne} /{ }^{22} \mathrm{Ne}$ and ${ }^{36} \mathrm{Ar} /{ }^{40} \mathrm{Ar}$ in the gas excess should remain between the atmospheric ratio and the ratio at atmospheric solubility equilibrium if fractionation occurs according to the CE-model, but might be significantly smaller if the fractionation depends on the differences in molecular diffusivities (PR-model). Because the ${ }^{3} \mathrm{He} /{ }^{4} \mathrm{He}$ ratio is affected by radiogenic/tritiogenic and terrigenic sources and the ${ }^{36} \mathrm{Ar} /{ }^{40} \mathrm{Ar}$ ratio is also influenced by terrigenic sources in aquifers with very large groundwater ages (e.g., Beyerle et al., 2000b; Torgersen et al., 1989), the ${ }^{20} \mathrm{Ne} /{ }^{22} \mathrm{Ne}$ ratio is the most reliable noble gas isotope ratio to test the fractionation models. The ${ }^{36} \mathrm{Ar} /{ }^{38} \mathrm{Ar}$ ratio could in principle also be used, although it is less sensitive to fractionation than the ${ }^{20} \mathrm{Ne} /{ }^{22} \mathrm{Ne}$ ratio, but to our knowledge it has never been measured in groundwater studies, due to the high experimental requirements (good mass resolution needed to separate ${ }^{38} \mathrm{Ar}$ from ${ }^{40} \mathrm{Ar}$ ). Although molecular diffusivities differ much more between heavy noble gases and $\mathrm{Ne}$ than between ${ }^{20} \mathrm{Ne}$ and ${ }^{22} \mathrm{Ne}$ (Table 1), the ${ }^{20} \mathrm{Ne} /{ }^{22} \mathrm{Ne}$ ratio is best suited to distinguish between the PR- and the CE-model because its dependence on recharge temperature is negligible and the ${ }^{20} \mathrm{Ne} /{ }^{22} \mathrm{Ne}$ ratio can be measured with a much higher precision (typically $0.2 \%$ ) than the concentrations of elemental noble gases (typically 1 to $2 \%$ ).

\subsection{Analysis of Noble Gas Data using the Software NOBLE}

Noble gas data analysis with respect to recharge temperature, excess air and its fractionation is commonly performed by inverse fitting based on $\chi^{2}$-minimization, which takes the error of the measurements into account (Aeschbach-Hertig et al., 1999). The new fitting program Noble developed for this study extends the original fitting procedure of Aeschbach-Hertig et al. (1999) by incorporating the CE-model and including the possibility to consider not only elemental noble gas concentrations but also concentrations of noble gas isotopes and noble gas isotope ratios. Commonly the three unknown parameters $T, A_{p r}$, $F_{p r}$ or $T, A_{c e}, F_{c e}$, respectively, are estimated from 4 observables, i.e., the concentration of $\mathrm{Ne}, \mathrm{Ar}, \mathrm{Kr}$ and $\mathrm{Xe}$. Pressure $P$ and salinity $S$ at recharge are prescribed. Considering the ${ }^{20} \mathrm{Ne} /$ ${ }^{22} \mathrm{Ne}$ and/or the ${ }^{36} \mathrm{Ar} /{ }^{40} \mathrm{Ar}$ ratios in addition to the elemental concentrations increases the number of observables and hence allows to estimate additional parameters (e.g., $P$ if the location of recharge is unknown) or can be used to improve the constraint on the fit parameters.

Noble extends the original parameter set employed in Aeschbach-Hertig et al. (1999) by including optional parameters that describe the concentrations of terrigenic ${ }^{4} \mathrm{He}$ and tritiogenic ${ }^{3} \mathrm{He}$, as well as the terrigenic ${ }^{3} \mathrm{He} /{ }^{4} \mathrm{He}$ ratio. An additional scaling parameter enables analysis based on the relative concentrations of the noble gases if the scaling of the absolute concentrations is unknown (e.g., unknown sample weight). A similar scaling technique has been used to interpret noble gas data from natural gas deposits where the degassing water volume is unknown (Ballentine et al., 1999). Furthermore, Noble supports ensemble fitting, i.e., the model parameters can be fitted not only to the gas concentrations of individual water samples separately but also to the concentrations from an ensemble of samples simultaneously. Thereby some of the fit parameters can be assumed to have the same value for all samples while other parameters may differ between samples. Propagation of the error of the measurements is performed by linear error propagation and optionally by a Monte-Carlo procedure to provide errors of the fit parameters. Both methods assume that measurement errors are normally distributed and independent. Noble calculates the probability $\mathrm{p}\left(\chi^{2}\right)$ for the minimum $\chi^{2}$ obtained from the fitting to be observed at the given number of freedoms. This provides the possibility to apply a $\chi^{2}$-test to the models. Noble provides the probability $\mathrm{p}\left(\chi^{2}\right)$ for each water sample separately and for the entire data set $\mathrm{p}\left(\chi_{\text {set }}^{2}\right)$, where $\chi_{\text {set }}^{2}$ is the sum of the $\chi^{2}$ values obtained for the samples of the data set. NOBLE will be made available on the Internet (http://www.eawag.ch/research_e/w+t/UI/ noblegasmethod.html).

\section{STUDY AREA AND DATA}

Details on the study area and an extended data set are given in Beyerle et al. (2002). In brief, groundwater samples were taken from the Continental Terminal (CT) aquifers located in south-western Niger, Africa, between 12.5 to $14.5^{\circ} \mathrm{N}$ and 2.5 to $4.5^{\circ} \mathrm{E}$ (Fig. 2). Within the $\mathrm{CT}$ formation three different aquifer compartments can be distinguished (CT3, CT2, CT1). CT3 is mostly unconfined, whereas CT2 and CT1 are confined. The Continental Terminal aquifer system is separated against the underlying Continental Intercalaire aquifer (CI) by massive low-permeable sediments mainly consisting of clays (Andrews et al., 1994). The altitude of the investigated area is almost constant increasing only slightly from $200 \mathrm{~m}$ to $300 \mathrm{~m}$ a.s.l. in north-easterly direction. The recharge area of the CT2 aquifer is located in the northern part of the study area and has an average altitude of $300 \mathrm{~m}$ a.s.l whereas the recharge areas of the CT1 and CI aquifers are further to the north at a mean altitude of $\sim 350$ to $400 \mathrm{~m}$.

Groundwater samples were collected in April 1999 and June 2000 from drinking water wells either operated by manual pumps or by electric submersible pumps. In all samples, concentrations of the noble gas isotopes ${ }^{3} \mathrm{He},{ }^{4} \mathrm{He},{ }^{20} \mathrm{Ne},{ }^{22} \mathrm{Ne}$, ${ }^{36} \mathrm{Ar},{ }^{40} \mathrm{Ar},{ }^{86} \mathrm{Kr}$ and ${ }^{136} \mathrm{Xe}$ were analysed according to the methods described in Beyerle et al. (2000a).

\section{RESULTS AND DISCUSSION}

\subsection{Comparison of Gas Exchange Models}

Figure 3 compares the model results from the PR- and the CE-model on recharge temperature for the $\mathrm{CT}$ aquifers derived by inverse fitting of the concentrations of $\mathrm{Ne}, \mathrm{Ar}, \mathrm{Kr}$ and $\mathrm{Xe}$. Recharge temperatures are displayed as function of terrigenic ${ }^{4} \mathrm{He}\left({ }^{4} \mathrm{He}_{\mathrm{ter}}\right)$, which can be interpreted as a qualitative measure of groundwater residence time because ${ }^{4} \mathrm{He}_{\text {ter }}$ (here of crustal origin) accumulates over time. ${ }^{4} \mathrm{He}_{\mathrm{ter}}$ is the difference between the measured ${ }^{4} \mathrm{He}$ concentration and the concentration of ${ }^{4} \mathrm{He}$ of atmospheric origin $\left({ }^{4} \mathrm{He}_{\mathrm{atm}}\right)$ determined from the PR- and the CE-model respectively. The concentration of atmospheric 


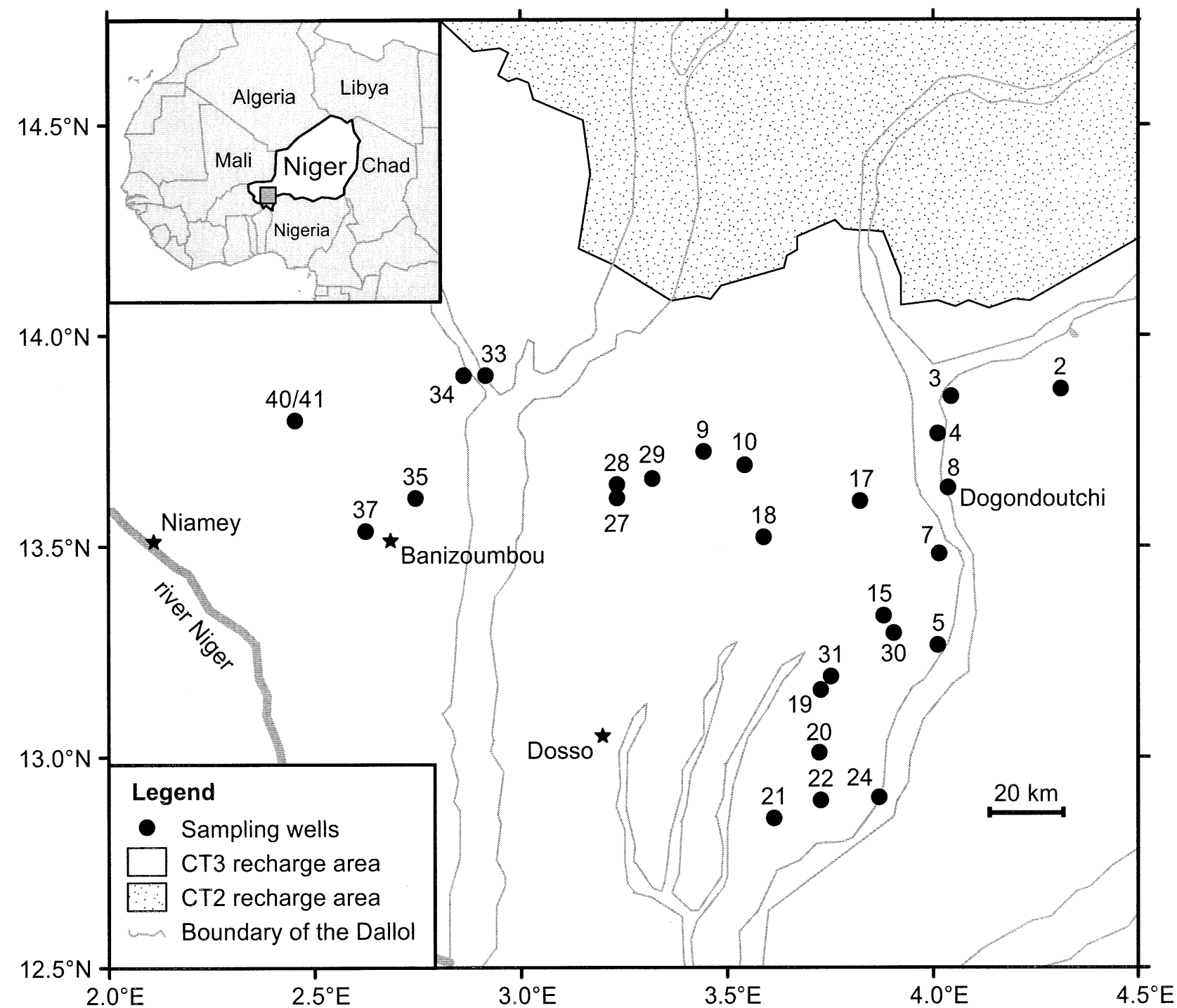

Fig. 2. Map of the investigated area including sampling locations. The altitude of the area is almost constant showing a slight gradient in north-eastern direction from $200 \mathrm{~m}$ to the CT2 recharge area at $\sim 300 \mathrm{~m}$ a.s.1. The CT1 and CI systems are recharged even further to the north-east or east at altitudes of $\sim 350$ to $400 \mathrm{~m}$. The depth of the unconfined groundwater table in the recharge zones varies between 5 and $20 \mathrm{~m}$ in the Dallols (dry, sand filled riverbeds) and between 20 and $60 \mathrm{~m}$ elsewhere.

origin is defined as the sum of two contributions: the atmospheric equilibrium concentration at $T, S$ and $P$ and the concentration due to fractionated excess air.

The model assuming unfractionated excess air has to be rejected according to the $\chi^{2}$-test, making it necessary to account for fractionation. Both the PR-model and the CE-model predict $\mathrm{Ne}, \mathrm{Ar}, \mathrm{Kr}$ and $\mathrm{Xe}$ concentrations compatible with the data. The PR-model (open symbols, Fig. 3) yields systematically higher recharge temperatures than the CE-model (solid symbols, Fig. 3 ), on average by $1.5^{\circ} \mathrm{C}$ and for the 3 oldest samples even by $\sim 4^{\circ} \mathrm{C}$. The difference in recharge temperature between young samples $\left({ }^{4} \mathrm{He}_{\mathrm{ter}}<1.5 \cdot 10^{-7} \mathrm{~cm}^{3} \mathrm{STPg}^{-1} ; \mathrm{n}=17\right)$ and intermediate samples $\left(1.5 \cdot 10^{-7} \mathrm{~cm}^{3} \mathrm{STPg}^{-1}<{ }^{4} \mathrm{He}_{\text {ter }}<1.5 \cdot 10^{-6}\right.$ $\left.\mathrm{cm}^{3} \mathrm{STPg}^{-1} ; \mathrm{n}=7\right)$ is about the same for the PR-model $(\Delta T=$ $\left.4.0^{\circ} \mathrm{C} \pm 1.8^{\circ} \mathrm{C}\right)$ and the CE-model $\left(4.8^{\circ} \mathrm{C} \pm 1.3^{\circ} \mathrm{C}\right)$. A thorough discussion of paleo-climatic conditions in Niger based on a more comprehensive data set on tracers from the CT Aquifers is given elsewhere (Beyerle et al., 2002). Here we focus on the use of $\mathrm{Ne}$ isotopes to distinguish between the two models.

Figure 4 compares the measured ${ }^{20} \mathrm{Ne} /{ }^{22} \mathrm{Ne}$ (Fig. 4a) and ${ }^{36} \mathrm{Ar} /{ }^{40} \mathrm{Ar}$ ratios (Fig. 4b) with those predicted from the PRmodel (open symbols) and the CE-model (solid symbols). The model parameters were derived by inverse fitting of $\mathrm{Ne}, \mathrm{Ar}, \mathrm{Kr}$ and Xe concentrations. The agreement between data and model prediction is significantly better for the CE-model than for the PR-model. Within error almost all measured ${ }^{20} \mathrm{Ne} /{ }^{22} \mathrm{Ne}$ ratios $\left(\left({ }^{20} \mathrm{Ne} /{ }^{22} \mathrm{Ne}\right)_{\mathrm{m}}\right)$ fall in the range between the isotopic ratio in the atmosphere (Ozima and Podosek, 1983) (Fig. 4a dashed lines, $\left.\mathrm{z}_{20 \mathrm{Ne}} / \mathrm{z}_{22 \mathrm{Ne}}\right)$ and the isotopic ratio at atmospheric equilibrium (Beyerle et al., 2000a) (Fig. 4a dotted lines, ${ }^{20} \mathrm{Ne}^{*} /$ $\left.{ }^{22} \mathrm{Ne}^{*}\right)$. Considering the standard deviation of all data, the mean of the measured ${ }^{20} \mathrm{Ne} /{ }^{22} \mathrm{Ne}$ and ${ }^{36} \mathrm{Ar} /{ }^{40} \mathrm{Ar}$ ratios are consistent 


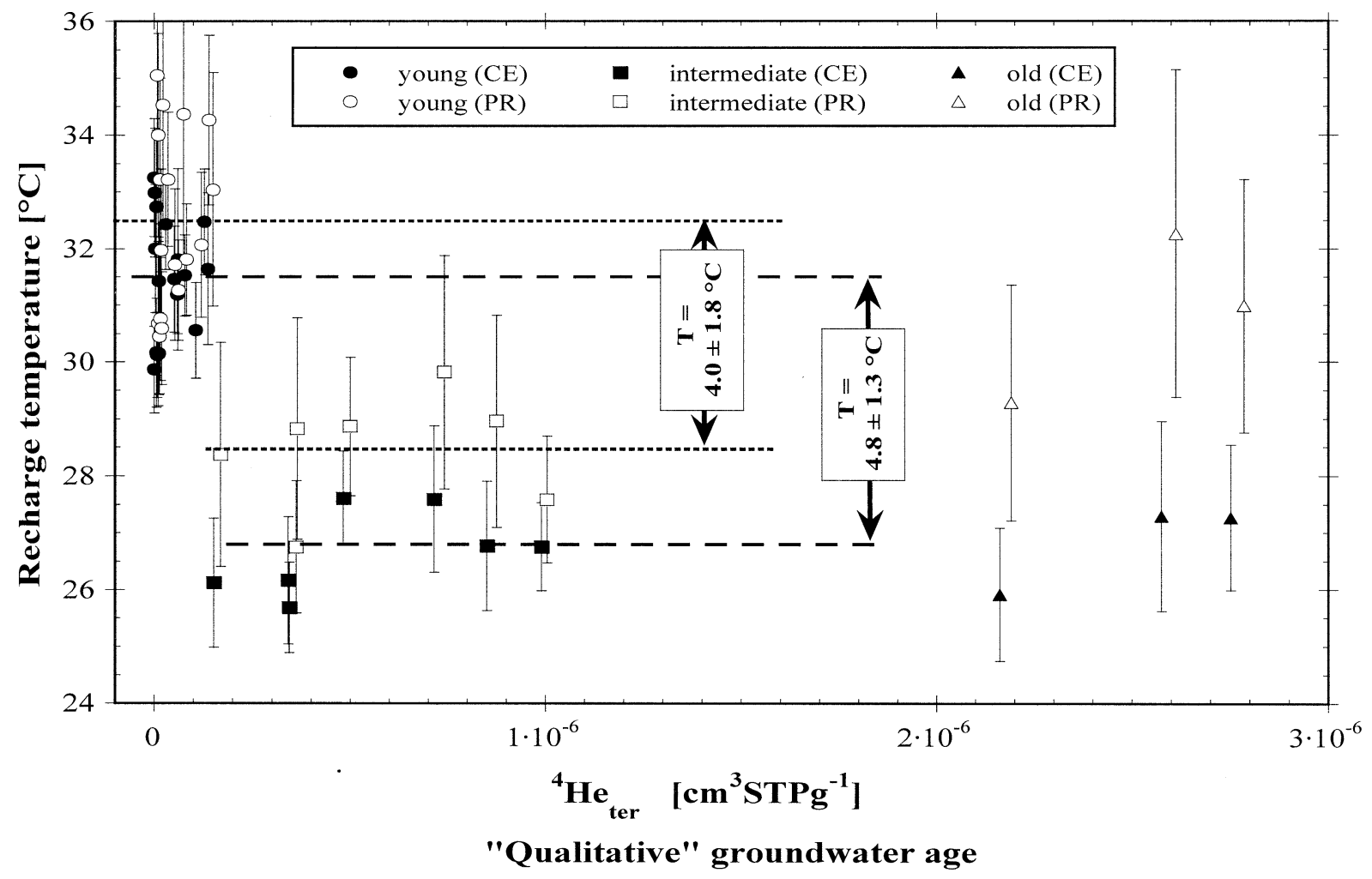

Fig 3. Recharge temperature as function of ${ }^{4} \mathrm{He}_{\text {ter }}$ determined by inverse fitting based on the noble gas concentrations $\mathrm{Ne}$, $\mathrm{Ar}, \mathrm{Kr}$ and $\mathrm{Xe}$ using the CE-model (solid symbols) and the PR-model (open symbols). Fit parameters are $T, A_{c e}$ and $F_{c e}$ in case of the CE-model and $T, A_{p r}$ and $F_{p r}$ in case of the PR-model. ${ }^{4} \mathrm{He}_{\text {ter }}$ can be interpreted as a qualitative groundwater age, because in groundwaters terrigenic helium accumulates over time.

with a value between the corresponding ratios in the atmosphere and at atmospheric equilibrium (Table 2).

As discussed above, fractionation described by the CEmodel always predicts isotopic ratios in the range between the values for air and atmospheric equilibrium. The PR-model however may predict isotopic ratios below this range as is demonstrated in the case of the CT Aquifers (Fig. 4 open symbols, Table 2).

The constraint on the fit-parameters $T, A$ and $F$ can be increased if the measured ${ }^{20} \mathrm{Ne} /{ }^{22} \mathrm{Ne}$ ratio is included as an observable in addition to the noble gas concentrations of $\mathrm{Ne}$, $\mathrm{Ar}, \mathrm{Kr}$, and $\mathrm{Xe}$. Using this extended data set, the CE-model yields a good fit $\left(\mathrm{p}\left(\chi_{\text {set }}^{2}=67\right) \approx 11 \%\right)$, whereas the PR-model has to be rejected $\left(\mathrm{p}\left(\chi_{\text {set }}^{2}=440\right)<<1 \%\right)$. This result reflects the fact that the measured ${ }^{20} \mathrm{Ne} /{ }^{22} \mathrm{Ne}$ ratios agree better with the predictions according to the CE-model than with the predictions according to the PR-model.

The best fit values for the parameters of the CE-model derived for the extended data set with the ${ }^{20} \mathrm{Ne} /{ }^{22} \mathrm{Ne}$ ratio included are essentially the same as those derived from the elemental concentrations of $\mathrm{Ne}, \mathrm{Ar}, \mathrm{Kr}$ and $\mathrm{Xe}$ only. In contrast, including the ${ }^{20} \mathrm{Ne} /{ }^{22} \mathrm{Ne}$ ratio reduces the best fit values for $F_{p r}$ of the PR-model by a factor of 10 , resulting in $F_{p r}$ ranging from 0 to 0.27 with a mean of $F_{p r}=0.1 \pm 0.1$. This implies that the predicted fractionation is small and that the PR-model essentially reduces to the UA-model. The constraint provided by the measured $\mathrm{Ne}$ isotopes ratios rules out significant diffusive gas loss.
Because the PR-model is incompatible with the data when considering measured ${ }^{20} \mathrm{Ne} /{ }^{22} \mathrm{Ne}$ ratios, only the CE-model adequately describes the gas exchange in the $\mathrm{CT}$ aquifers. Thus in case of the $\mathrm{CT}$ aquifers the parameters describing recharge temperature, gas excess and its fractionation derived by inverse fitting of $\mathrm{Ne}, \mathrm{Ar}, \mathrm{Kr}, \mathrm{Xe}$ and the ${ }^{20} \mathrm{Ne} /{ }^{22} \mathrm{Ne}$ ratio using the CE-model should be employed in the discussion of paleoclimatic change and for the calculation of ${ }^{3} \mathrm{He}_{\mathrm{atm}}$ and ${ }^{4} \mathrm{He}_{\mathrm{atm}}$ for dating purposes.

Observed ${ }^{20} \mathrm{Ne} /{ }^{22} \mathrm{Ne}$ ratios fall within the range between the ratio in the atmosphere and the ratio at atmospheric equilibrium not only in the CT aquifers of Niger but also in other aquifers where fractionated excess gas has been reported. AeschbachHertig et al. (2000) analysed four data sets, but Ne isotope data are unfortunately available only for two of them (Belgium and Oman). In both cases no significant fractionation of the $\mathrm{Ne}$ isotopes was observed, e.g., in northern Oman (Weyhenmeyer et al., 2000) the ${ }^{20} \mathrm{Ne} /{ }^{22} \mathrm{Ne}$ ratio measured in 9 samples ranges between 9.763 and 9.865 with a mean of $9.795 \pm 0.029$. This supports the applicability of the CE-model in noble gas based paleo-studies and for groundwater age dating. However, it does not necessarily exclude the PR-model. The PR- and the CEmodel only describe the mean effect of gas exchange on noble gases and do not resolve details on the interaction between gas excess, entrapped air and recharging groundwater. Therefore, it is still unclear which environmental conditions lead to the noble gas pattern described by the PR-model and which result in the noble gas pattern described by the CE-model. Thus, 

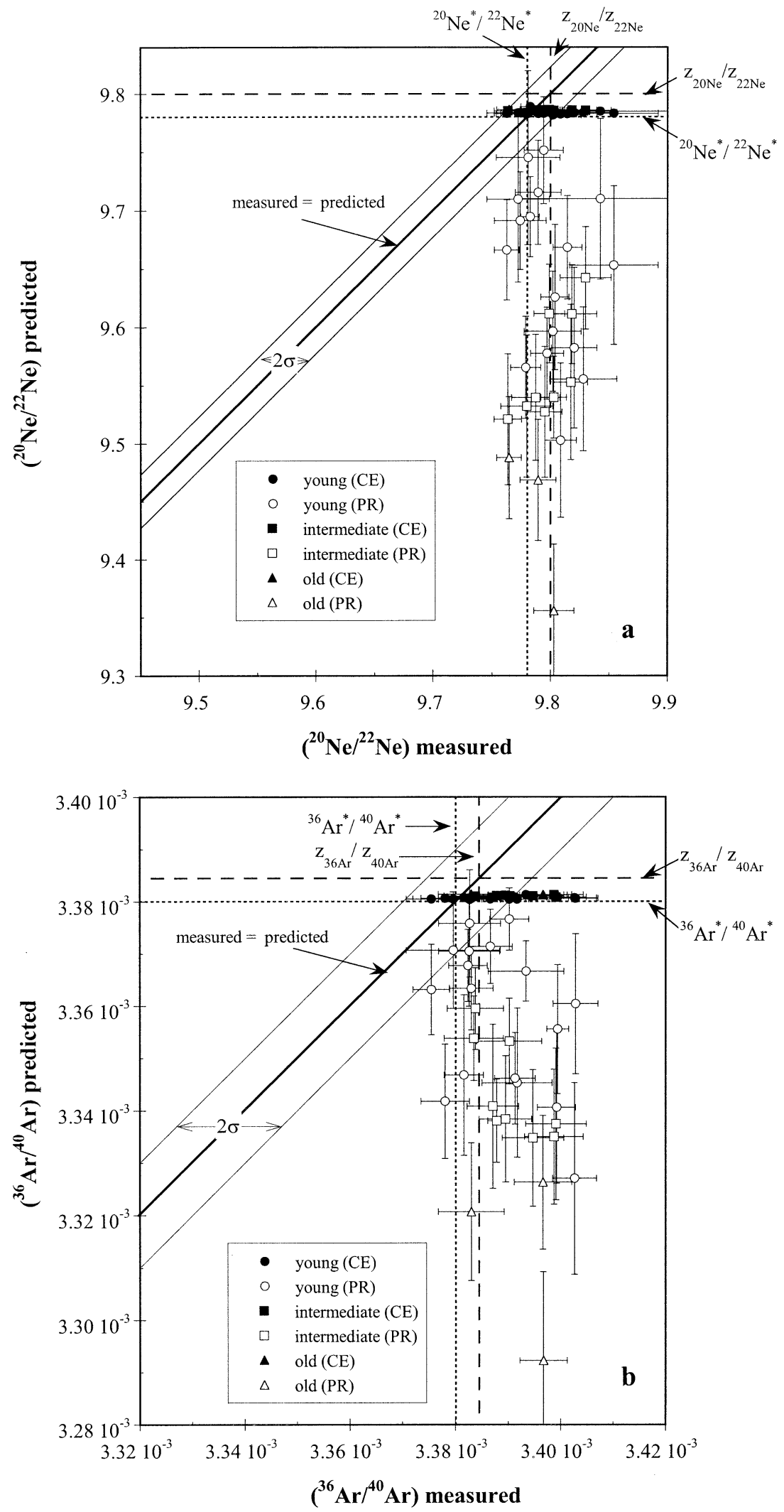

Fig. 4. Comparison of measured and predicted ${ }^{20} \mathrm{Ne} / 22 \mathrm{Ne}$ and ${ }^{36} \mathrm{Ar} /{ }^{40} \mathrm{Ar}$ ratios. Predictions were calculated from the model parameters describing recharge temperature, excess air and its fractionation derived with the CE-model (solid symbols) and PR-model (open symbols), respectively. Model parameters were obtained by inverse fitting to the concentrations of $\mathrm{Ne}, \mathrm{Ar}, \mathrm{Kr}$ and $\mathrm{Xe}$. 
Table 2. Mean measured and predicted ${ }^{20} \mathrm{Ne} /{ }^{22} \mathrm{Ne}$ and ${ }^{36} \mathrm{Ar} /{ }^{40} \mathrm{Ar}$ ratios in comparison with the corresponding ratios in the atmosphere and in atmospheric equilibrium.

\begin{tabular}{lcc}
\hline & ${ }^{20} \mathrm{Ne} /{ }^{22} \mathrm{Ne}$ & $\begin{array}{c}{ }^{36} \mathrm{Ar} /{ }^{40} \mathrm{Ar} \\
\left(10^{-3}\right)\end{array}$ \\
\hline $\begin{array}{l}\text { Mean of measurements } \\
\text { Mean of predicted ratios using the } \\
\quad \text { PR-model }\end{array}$ & $9.798 \pm 0.024$ & $3.390 \pm 0.008$ \\
$\begin{array}{l}\text { Mean of predicted ratios using the } \\
\quad \text { CE-model }\end{array}$ & $9.785 \pm 0.095$ & $3.350 \pm 0.020$ \\
$\begin{array}{l}\text { Isotope ratios in the atmosphere } \\
\text { (Ozima and Podosek, 1983) }\end{array}$ & $9.381 \pm 0.0003$ \\
$\begin{array}{l}\text { Isotope ratios in atmospheric } \\
\text { equilibrium (Beyerle et al., }\end{array}$ & 9.7804 & 3.384 \\
2000a) & & 3.380 \\
\hline
\end{tabular}

whether the PR- or the CE-model should be applied in a specific aquifer can be judged only from data on concentrations of noble gases and their isotopes.

\subsection{Dating Applications}

Groundwater dating with the ${ }^{3} \mathrm{H}_{-}{ }^{3} \mathrm{He}$ method requires estimation of tritiogenic ${ }^{3} \mathrm{He}\left({ }^{3} \mathrm{He}_{\text {tri }}\right)$ by subtracting ${ }^{3} \mathrm{He}_{\text {atm }}$ and terrigenic ${ }^{3} \mathrm{He}\left({ }^{3} \mathrm{He}_{\text {ter }}\right)$ from the measured ${ }^{3} \mathrm{He}\left({ }^{3} \mathrm{He}_{\mathrm{m}}\right)$ concentrations. Assuming that ${ }^{3} \mathrm{He}_{\mathrm{atm}},{ }^{4} \mathrm{He}_{\mathrm{atm}}$ and the ${ }^{3} \mathrm{He} /{ }^{4} \mathrm{He}$ ratio of the terrigenic component $\left({ }^{3} \mathrm{He} /{ }^{4} \mathrm{He}\right)_{\text {ter }}$ is known, ${ }^{3} \mathrm{He}_{\text {tri }}$ can be calculated from the balance of ${ }^{4} \mathrm{He}$ and ${ }^{3} \mathrm{He}$ (e.g., Schlosser et al., 1989):

$$
\begin{aligned}
{ }^{4} \mathrm{He} \text { ter } & ={ }^{4} \mathrm{He}_{m}- \\
& { }^{4} \mathrm{He} e_{\text {atm }}{ }^{3} \mathrm{He} e_{\text {tri }}={ }^{3} \mathrm{He} e_{m}-{ }^{3} \mathrm{He} e_{\text {atm }}-{ }^{4} \mathrm{He} e_{\text {ter }} \cdot\left(\frac{{ }^{3} \mathrm{He}}{{ }^{4} \mathrm{He}}\right)_{\text {ter }}
\end{aligned}
$$

\subsubsection{Estimation of ${ }^{3} \mathrm{He}_{\text {atm }}$ and ${ }^{4} \mathrm{He} e_{\text {atm }}$}

The ${ }^{3} \mathrm{He}$ and ${ }^{4} \mathrm{He}$ components of atmospheric origin can be estimated from the ${ }^{3} \mathrm{He}$ and ${ }^{4} \mathrm{He}$ concentrations in the atmosphere (Ozima and Podosek, 1983) together with the ${ }^{3} \mathrm{He}$ and ${ }^{4} \mathrm{He}$ solubilities (Benson and Krause, 1980; Weiss, 1971) by employing an appropriate gas exchange model (e.g., the PR- or the CE-model) where model parameters describing gas excess and fractionation have been estimated by inverse fitting of noble gas concentrations. In case of the CT aquifers in Niger estimated ${ }^{3} \mathrm{He}_{\text {atm }}$ and ${ }^{4} \mathrm{He}_{\text {atm }}$ differ substantially between the PR- and CE- model if the inverse fitting procedure is based only on the elemental concentrations of $\mathrm{Ne}, \mathrm{Ar}, \mathrm{Kr}$ and $\mathrm{Xe}$ (Fig. 5a, Table 3).

If the measured ${ }^{20} \mathrm{Ne} /{ }^{22} \mathrm{Ne}$ ratio is included as additional observable, ${ }^{3} \mathrm{He}_{\mathrm{atm}}$ and ${ }^{4} \mathrm{He}_{\text {atm }}$ predicted with the PR-model increase substantially and closely agree with predictions assuming unfractionated excess air (Table 3). Predictions of ${ }^{3} \mathrm{He}_{\text {atm }}$ and ${ }^{4} \mathrm{He}_{\mathrm{atm}}$ based on the CE-model are independent of whether the $\left({ }^{20} \mathrm{Ne} /{ }^{22} \mathrm{Ne}\right)_{\mathrm{m}}$ is included in the parameter estimation or not (see Table 3). Because only the CE-model is compatible with the measured elemental noble gas concentrations and the ${ }^{20} \mathrm{Ne} /{ }^{22} \mathrm{Ne}$ ratio (see above) the ${ }^{3} \mathrm{He}_{\text {atm }}$ and ${ }^{4} \mathrm{He}_{\text {atm }}$ predicted with the CE-model are assumed to correspond to the true values.
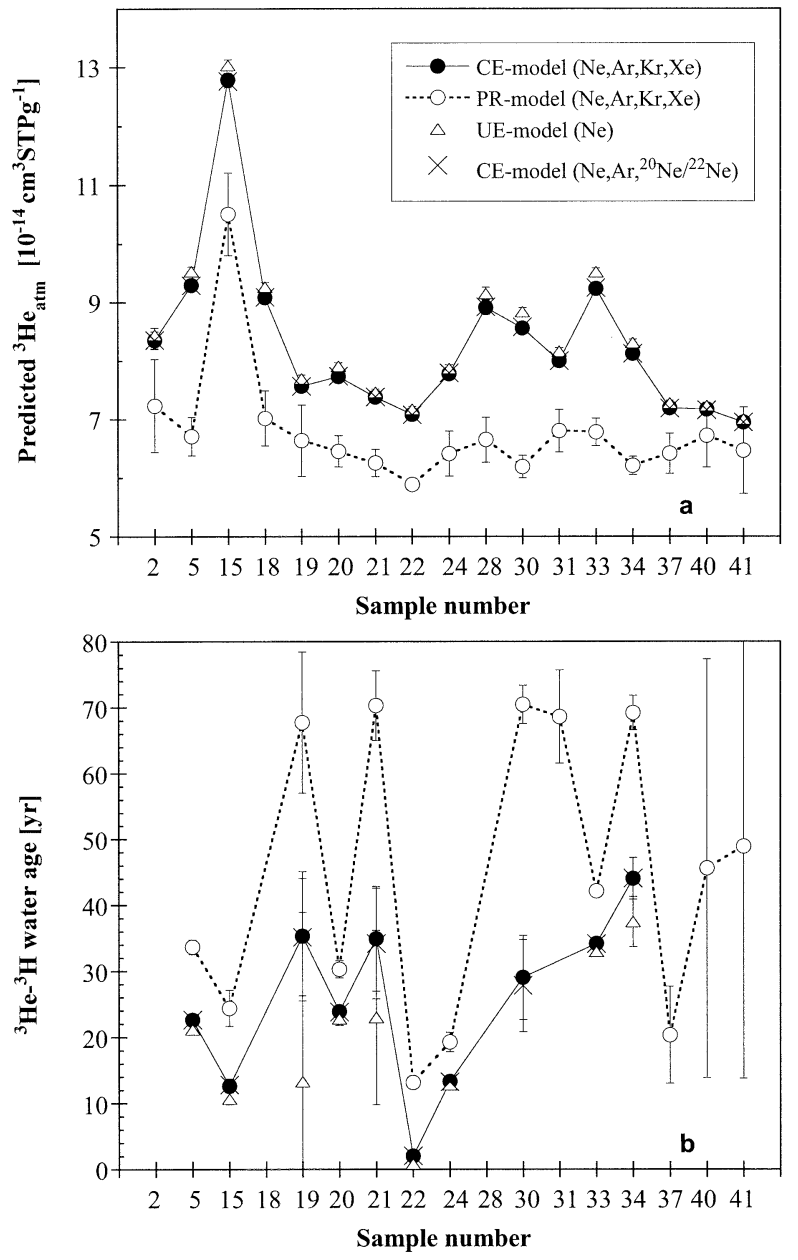

Fig. 5. ${ }^{3} \mathrm{He}_{\text {atm }}$ and ${ }^{3} \mathrm{H}-{ }^{3} \mathrm{He}$ water ages for young groundwaters of the CT aquifers. Concentrations of ${ }^{3} \mathrm{He}_{\text {atm }}$ are shown for all samples with $\mathrm{He}_{\text {ter }}<1.5 \cdot 10^{-7} \mathrm{~cm}^{3} \mathrm{STPg}^{-1}$, which all infiltrated at similar temperatures of $\sim 32^{\circ} \mathrm{C}$ (see Fig. 2a). ${ }^{3} \mathrm{H}_{-}{ }^{3} \mathrm{He}$ water ages are shown for all samples in which ${ }^{3} \mathrm{H}$ has been detected and ${ }^{3} \mathrm{He}_{\text {tri }}$ is significantly larger than zero (b). Results from the PR-model and the CE-model based on $\mathrm{Ne}, \mathrm{Ar}, \mathrm{Kr}$ and $\mathrm{Xe}$ are presented and compared to results from simplified procedures which are based on Ne only and on the combination of $\mathrm{Ne}, \mathrm{Ar}$ and ${ }^{20} \mathrm{Ne} /{ }^{22} \mathrm{Ne}$. The ${ }^{3} \mathrm{H}-{ }^{3} \mathrm{He}$ water ages were calculated assuming $\left({ }^{3} \mathrm{He} /{ }^{4} \mathrm{He}\right)_{\mathrm{ter}}=(2.2 \pm 0.1) \cdot 10^{-8}$ except in the case of the PR-model where $\left({ }^{3} \mathrm{He} /{ }^{4} \mathrm{He}\right)_{\text {ter }}=(3.0 \pm 0.1) \cdot 10^{-8}$ was used.

\subsubsection{Estimation of $\left({ }^{3} \mathrm{He} /{ }^{4} \mathrm{He}\right)_{\text {ter }}$ and natural (pre-bomb) Tritium}

By restriction to samples that are not influenced by bomb tritium, the values of $\left({ }^{3} \mathrm{He} /{ }^{4} \mathrm{He}\right)_{\text {ter }}$ and the ${ }^{3} \mathrm{He}_{\text {tri }}$ of prebomb origin can be estimated by inverse fitting utilising the ensemble fitting option of Noble. To this end, noble gas concentrations and isotope ratios from all intermediate and old groundwater samples $\left({ }^{4} \mathrm{He}_{\text {ter }}>1.5 \cdot 10^{-7} \mathrm{~cm}^{3} \mathrm{STPg}^{-1} ; 10\right.$ samples $)$ were compiled into a data ensemble. The fit-parameters $T, A$ and $F$ determining the noble gas concentration of atmospheric origin and the fit parameter describing the concentration of ${ }^{4} \mathrm{He}_{\text {ter }}$ are assumed to be different for each water sample. $\left({ }^{3} \mathrm{He} /{ }^{4} \mathrm{He}\right)_{\text {ter }}$ and prebomb ${ }^{3} \mathrm{He}_{\text {tri }}$ are assumed to be the same for all water samples, i.e., for the data ensemble. 
Table 3. The effect of model choice and availability of data on $\chi^{2}$ set and predicted ${ }^{3} \mathrm{He}_{\mathrm{atm}}$. Data originate from young goundwater samples ( $\mathrm{n}=17$ ) of the CT aquifers in Niger. ${ }^{3} \mathrm{He}_{\text {atm }}$ predicted from the CE-model based on $\mathrm{Ne}, \mathrm{Ar}, \mathrm{Kr}, \mathrm{Xe}$ and ${ }^{20} \mathrm{Ne} /{ }^{22} \mathrm{Ne}$ serves as reference. The degrees of freedom in the fits are given for the entire data set by $\nu_{\text {set }}$.

\begin{tabular}{|c|c|c|c|c|c|c|}
\hline \multirow[b]{2}{*}{ Data considered } & \multirow{2}{*}{$\begin{array}{l}\text { Parameters } \\
\text { fitted }\end{array}$} & \multirow{2}{*}{$\begin{array}{l}\text { Parameters } \\
\text { prescribed }\end{array}$} & \multirow[b]{2}{*}{$\chi_{\mathrm{set}}^{2}$} & \multirow[b]{2}{*}{$\nu_{\text {set }}$} & \multicolumn{2}{|c|}{$\begin{array}{c}\text { Deviation of }{ }^{3} \mathrm{He}_{\mathrm{atm}} \text { from the } \\
\text { best estimate }(\%)\end{array}$} \\
\hline & & & & & minimum & maximum \\
\hline \multicolumn{7}{|l|}{ CE-model } \\
\hline $\mathrm{Ne}, \mathrm{Ar}, \mathrm{Kr}, \mathrm{Xe},{ }^{20} \mathrm{Ne} /{ }^{22} \mathrm{Ne}$ & $T, A_{c e}, F_{c e}$ & - & 38 & 34 & 0 & 0 \\
\hline $\mathrm{Ne}, \mathrm{Ar}, \mathrm{Kr}, \mathrm{Xe}$ & $T, A_{c e}, F_{c e}$ & - & 8 & 17 & -0.06 & +0.04 \\
\hline $\mathrm{Ne}, \mathrm{Ar}$ & $A_{c e}, F_{c e}$ & $T=32^{\circ} \mathrm{C}$ & 0 & 0 & -0.2 & +0.2 \\
\hline $\mathrm{Ne},{ }^{20} \mathrm{Ne} /{ }^{22} \mathrm{Ne}$ & $A_{c e}, F_{c e}$ & $T=32^{\circ} \mathrm{C}$ & 24 & 0 & -3.9 & +3.2 \\
\hline $\mathrm{Ne}, \mathrm{Ar},{ }^{20} \mathrm{Ne} /{ }^{22} \mathrm{Ne}$ & $A_{c e}, F_{c e}$ & $T=32^{\circ} \mathrm{C}$ & 29 & 17 & -0.2 & +0.2 \\
\hline $\mathrm{Ne}, \mathrm{Ar},{ }^{20} \mathrm{Ne} /{ }^{22} \mathrm{Ne}$ & $A_{c e}, F_{c e}$ & $T=30^{\circ} \mathrm{C}$ & 50 & 17 & -0.8 & +0.2 \\
\hline $\mathrm{Ne}, \mathrm{Ar},{ }^{20} \mathrm{Ne} /{ }^{22} \mathrm{Ne}$ & $A_{c e}, F_{c e}$ & $T=35^{\circ} \mathrm{C}$ & 47 & 17 & -0.09 & +0.8 \\
\hline \multicolumn{7}{|l|}{ PR-model } \\
\hline $\mathrm{Ne}, \mathrm{Ar}, \mathrm{Kr}, \mathrm{Xe},{ }^{20} \mathrm{Ne} /{ }^{22} \mathrm{Ne}$ & $T, A_{c e}, F_{c e}$ & - & 176 & 34 & -5.4 & +1.7 \\
\hline $\mathrm{Ne}, \mathrm{Ar}, \mathrm{Kr}, \mathrm{Xe}$ & $T, A_{c e}, F_{c e}$ & - & 5 & 17 & -27.8 & -6.2 \\
\hline $\mathrm{Ne}, \mathrm{Ar}$ & $A_{c e}, F_{c e}$ & $T=32^{\circ} \mathrm{C}$ & 0 & 0 & -36.3 & -8.3 \\
\hline $\mathrm{Ne},{ }^{20} \mathrm{Ne} /{ }^{22} \mathrm{Ne}$ & $A_{c e}, F_{c e}$ & $T=32^{\circ} \mathrm{C}$ & 21 & 0 & -2.8 & +3.2 \\
\hline $\mathrm{Ne}, \mathrm{Ar},{ }^{20} \mathrm{Ne} /{ }^{22} \mathrm{Ne}$ & $A_{c e}, F_{c e}$ & $T=32^{\circ} \mathrm{C}$ & 570 & 17 & -14.8 & +2.3 \\
\hline \multicolumn{7}{|l|}{ UA-model } \\
\hline $\mathrm{Ne}, \mathrm{Ar}, \mathrm{Kr}, \mathrm{Xe},{ }^{20} \mathrm{Ne} /{ }^{22} \mathrm{Ne}$ & $T, A$ & $F=0$ & 191 & 51 & +0.4 & +2.6 \\
\hline $\mathrm{Ne}, \mathrm{Ar}, \mathrm{Kr}, \mathrm{Xe}$ & $T, A$ & $F=0$ & 164 & 34 & +0.4 & +2.6 \\
\hline $\mathrm{Ne}$ & $A$ & $T=32^{\circ} \mathrm{C} ; F=0$ & 0 & 0 & +0.7 & +3.2 \\
\hline $\mathrm{Ne}, \mathrm{Ar}$ & $A$ & $T=32^{\circ} \mathrm{C} ; F=0$ & 859 & 17 & +1.0 & +7.9 \\
\hline $\mathrm{Ne},{ }^{20} \mathrm{Ne} /{ }^{22} \mathrm{Ne}$ & $A$ & $T=32^{\circ} \mathrm{C} ; F=0$ & 27 & 17 & +0.7 & +3.2 \\
\hline $\mathrm{Ne}, \mathrm{Ar},{ }^{20} \mathrm{Ne} /{ }^{22} \mathrm{Ne}$ & $A$ & $T=32^{\circ} \mathrm{C} ; F=0$ & 886 & 34 & +1.0 & +8.5 \\
\hline
\end{tabular}

First we consider the data set consisting of the measured elemental concentrations of $\mathrm{He}, \mathrm{Ne}, \mathrm{Ar}, \mathrm{Kr}$, and $\mathrm{Xe}$ and the ${ }^{3} \mathrm{He} /{ }^{4} \mathrm{He}$ ratio for each of the 10 samples. Altogether 60 independent measurements are available for the inverse fitting of 42 fit parameters leaving 18 degrees of freedom. For this data set the CE-model gives $\left({ }^{3} \mathrm{He} /{ }^{4} \mathrm{He}\right)_{\text {ter }}=(2.2 \pm 0.1) \cdot 10^{-8}$ and ${ }^{3} \mathrm{He}_{\text {tri }}$ $=0.2 \pm 0.3 \mathrm{TU}\left(1 \mathrm{~cm}^{3} \mathrm{STPg}^{-1} \triangleq 4.019 \cdot 10^{14} \mathrm{TU}\right)$. The value of ${ }^{3} \mathrm{He}_{\text {tri }}$ corresponds to the concentration of prebomb tritium at the groundwater table. Prebomb ${ }^{3} \mathrm{H}$ close to zero is reasonable because radioactive decay during the water transport through the large unsaturated zone of the CT aquifers substantially reduces the tritium concentration reaching the saturated zone (Brennwald et al., 2001). ${ }^{4} \mathrm{He}_{\text {ter }}$ is different for each sample and can be used as a qualitative groundwater age as in Figure 3. If the PR-model is applied instead of the CE-model one obtains $\left({ }^{3} \mathrm{He} /{ }^{4} \mathrm{He}\right)_{\mathrm{ter}}=(3.0 \pm 0.1) \cdot 10^{-8}$ and ${ }^{3} \mathrm{He}_{\mathrm{tri}}=11 \pm 1 \mathrm{TU}$. Both values are significantly larger than those predicted by the CE-model. Including the ${ }^{20} \mathrm{Ne} /{ }^{22} \mathrm{Ne}$ ratios in the data set, 70 observables are available for the 42 fit parameters leaving 28 degrees of freedom. For the CE-model the predicted values of $\left({ }^{3} \mathrm{He} /{ }^{4} \mathrm{He}\right)_{\text {ter }}$ and ${ }^{3} \mathrm{He}_{\text {tri }}$ are the same as above. In case of the PR-model $\left({ }^{3} \mathrm{He} /{ }^{4} \mathrm{He}\right)_{\mathrm{ter}}=(2.1 \pm 0.2) \cdot 10^{-8}$ and ${ }^{3} \mathrm{He}_{\mathrm{tri}}=3 \pm 1$ TU. Both values are significantly smaller than those predicted without the ${ }^{20} \mathrm{Ne} /{ }^{22} \mathrm{Ne}$ ratios and closer to the results of the CE-model.

The parameters describing $\left({ }^{3} \mathrm{He} /{ }^{4} \mathrm{He}\right)_{\text {ter }},{ }^{4} \mathrm{He}_{\text {ter }}$ and ${ }^{3} \mathrm{He}_{\text {tri }}$ are only affected by concentrations of ${ }^{3} \mathrm{He}$ and ${ }^{4} \mathrm{He}$, whereas the parameters $T, A$ and $F$ are affected by the concentrations of all noble gas isotopes. Hence, one can prescribe the parameters $T$, $A_{c e}$, and $F_{c e}$ using the results from inverse fitting of $\mathrm{Ne}, \mathrm{Ar}, \mathrm{Kr}$ and $\mathrm{Xe}$, and fit only the parameters describing $\left({ }^{3} \mathrm{He} /{ }^{4} \mathrm{He}\right)_{\text {ter }}$, ${ }^{4} \mathrm{He}_{\text {ter }}$ and ${ }^{3} \mathrm{He}_{\text {tri }}$ to the measured He concentration and ${ }^{3} \mathrm{He} /{ }^{4} \mathrm{He}$ ratio. This procedure involves 20 measurements and 12 fit parameters, i.e., 8 degrees of freedom. It underestimates the errors of the values for $\left({ }^{3} \mathrm{He} /{ }^{4} \mathrm{He}\right)_{\text {ter }},{ }^{4} \mathrm{He}_{\text {ter }}$ and ${ }^{3} \mathrm{He}_{\text {tri }}$ because the uncertainties of $T, A_{c e}, F_{c e}$ are not propagated. The results for the two procedures are significantly different only in the case of the PR-model. However, for neither of the two procedures and models the model results are consistent with the data according to a $\chi^{2}$ test, indicating that the model assumption that $\left({ }^{3} \mathrm{He} /{ }^{4} \mathrm{He}\right)_{\text {ter }}$ and ${ }^{3} \mathrm{He}_{\text {tri }}$ are the same for all samples is too simplified to adequately describe the data set. Nevertheless the calculated values of $\left({ }^{3} \mathrm{He} /{ }^{4} \mathrm{He}\right)_{\text {ter }}$ and ${ }^{3} \mathrm{He}_{\text {tri }}$ are used as best estimates.

Figure 6a displays the predicted concentration of non-atmospheric ${ }^{3} \mathrm{He}$, i.e., the sum of ${ }^{3} \mathrm{He}_{\text {ter }}$ and ${ }^{3} \mathrm{He}_{\text {tri }}$, versus the predicted ${ }^{4} \mathrm{He}_{\text {ter }}$ for the PR- and the CE-model obtained from inverse fitting of $T, A_{p r}$, and $F_{p r}$ or $T, A_{c e}$ and $F_{c e}$, respectively, to the elemental concentrations of $\mathrm{Ne}, \mathrm{Ar}, \mathrm{Kr}$ and $\mathrm{Xe}$. The regression lines give in case of the CE-model $\left({ }^{3} \mathrm{He} /{ }^{4} \mathrm{He}\right)_{\text {ter }}=$ $(2.2 \pm 0.1) \cdot 10^{-8}$ and ${ }^{3} \mathrm{He}_{\mathrm{tri}}=0.4 \pm 0.2 \mathrm{TU}$ and in case of the PR-model $\left({ }^{3} \mathrm{He} /{ }^{4} \mathrm{He}\right)_{\mathrm{ter}}=(3.4 \pm 0.1) \cdot 10^{-8}$ and ${ }^{3} \mathrm{He}_{\mathrm{tri}}=12 \pm$ 1 TU. Fitting regression lines corresponds to the second approach taken above and confirms the results provided by the ensemble fitting using Noble.

In previous studies (e.g., Aeschbach-Hertig et al., 2000; Kipfer et al., 1994; Kipfer et al., 1996) $\left({ }^{3} \mathrm{He} /{ }^{4} \mathrm{He}\right)_{\text {ter }}$ has been derived from a regression line in a three isotope plot ${ }^{3} \mathrm{He} /$ ${ }^{4} \mathrm{He}$ vs $\mathrm{Ne} /{ }^{4} \mathrm{He}$ (Fig. 6b). Such a procedure assumes that all measured ratios can be interpreted as a mixture between a terrigenic component with constant $\left({ }^{3} \mathrm{He} /{ }^{4} \mathrm{He}\right)_{\text {ter }}$ and $(\mathrm{Ne} /$ $\mathrm{He})_{\text {ter }}=0$, and a combined atmospheric/tritiogenic component with constant composition given by $\left({ }^{3} \mathrm{He}_{\mathrm{atm}}+{ }^{3} \mathrm{He}_{\text {tri }}\right) /$ ${ }^{4} \mathrm{He}_{\mathrm{atm}}$ and $\mathrm{Ne}_{\mathrm{atm}} / \mathrm{He}_{\mathrm{atm}}$. Although these assumptions are not strictly fulfilled, the variations in the atmospheric/tritiogenic endmember (due to varying $T, A, F$, and ${ }^{3} \mathrm{He}_{\text {tri }}$ ) are relatively small compared to the effect of the terrigenic component. Therefore this approach yields a useful estimate of $\left({ }^{3} \mathrm{He} /\right.$ 

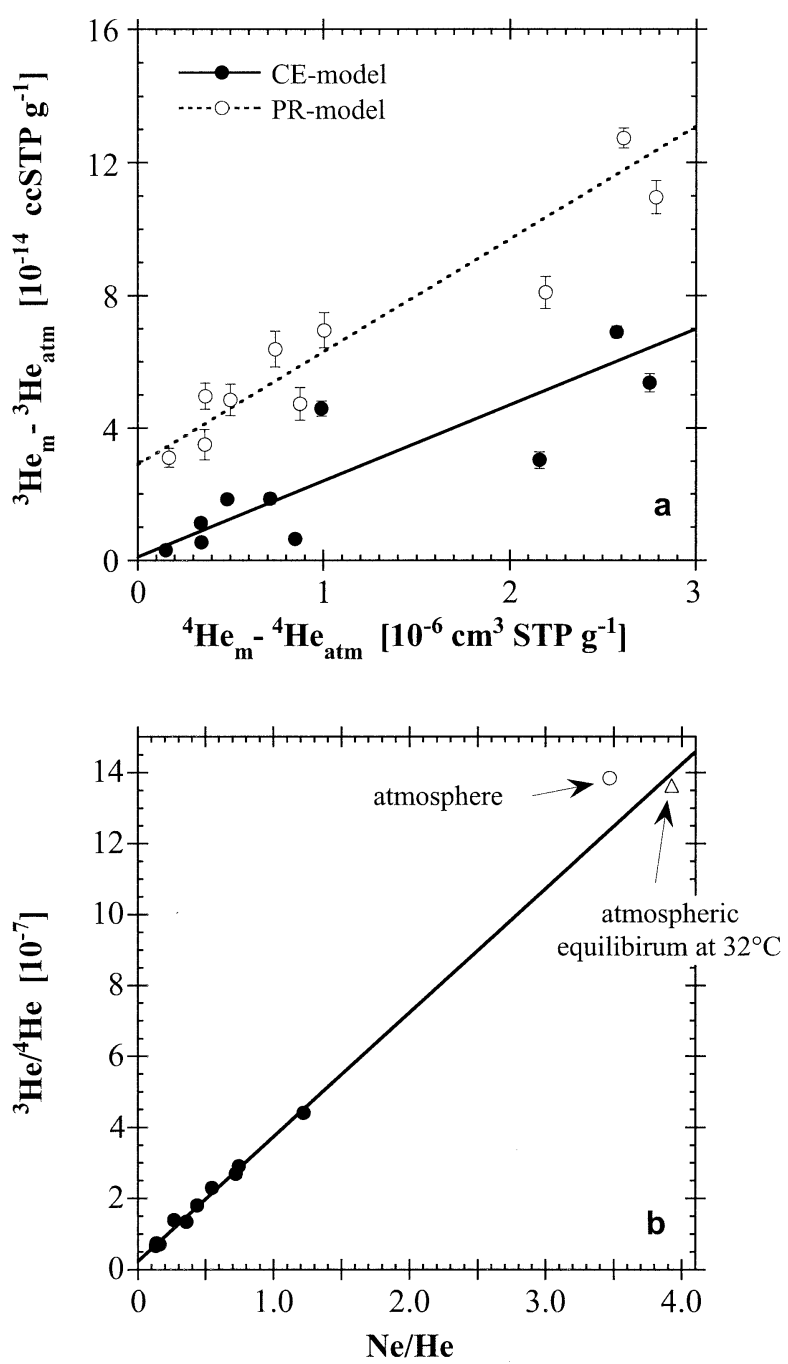

Fig. 6. Different methods to estimate $\left({ }^{3} \mathrm{He} /{ }^{4} \mathrm{He}\right)_{\text {ter }}$. (a) Non-atmospheric ${ }^{3} \mathrm{He}$ versus non-atmospheric ${ }^{4} \mathrm{He}$ for intermediate and old groundwater samples $\left(\mathrm{He}_{\text {ter }}>1.5 \cdot 10^{-7} \mathrm{~cm}^{3} \mathrm{STPg}^{-1}\right)$ from the CT aquifers. Assuming a constant prebomb tritium and a constant $\left({ }^{3} \mathrm{He} /\right.$ $\left.{ }^{4} \mathrm{He}\right)_{\text {ter }}$ the intercept of the regression line corresponds to ${ }^{3} \mathrm{He}_{\mathrm{tri}}$ and the slope corresponds to $\left({ }^{3} \mathrm{He} /{ }^{4} \mathrm{He}\right)_{\text {ter }}$. Based on the concentrations of $\mathrm{Ne}$, $\mathrm{Ar}, \mathrm{Kr}$, and $\mathrm{Xe},{ }^{3} \mathrm{He}_{\mathrm{m}}{ }^{-} \mathrm{He}_{\mathrm{atm}}$ and ${ }^{4} \mathrm{He}_{\mathrm{m}}{ }^{4} \mathrm{He}_{\mathrm{atm}}$ are determined using the PR-model (open circles) and the CE-model (solid circles), respectively.(b) Measured ${ }^{3} \mathrm{He} /{ }^{4} \mathrm{He}$ ratio versus the measured concentration ratio of $\mathrm{Ne}$ to $\mathrm{He}$. If the $\mathrm{He}$ concentration approaches infinity, the $\mathrm{Ne} / \mathrm{He}$ ratio approches zero and the atmospheric gas contribution becomes negligible compared to terrigenic contributions. Thus the intercept of the regression line in Fig. $5 \mathrm{~b}$ can be interpreted to correspond to $\left({ }^{3} \mathrm{He} /{ }^{4} \mathrm{He}\right)_{\text {ter }}$.

$\left.{ }^{4} \mathrm{He}\right)_{\mathrm{ter}}=(2.3 \pm 0.1) \cdot 10^{-8}$. This estimate agrees with the value found by the CE-model but is signifcantly lower than the value estimated from the PR-model based on the data set without the ${ }^{20} \mathrm{Ne} /{ }^{22} \mathrm{Ne}$ ratio.

\subsubsection{Estimation of water age of young groundwater samples}

The estimated values of $\left({ }^{3} \mathrm{He} /{ }^{4} \mathrm{He}\right)_{\mathrm{ter}},{ }^{3} \mathrm{He}_{\mathrm{atm}}$ and ${ }^{4} \mathrm{He}_{\mathrm{atm}}$ from the different models can be employed to estimate ${ }^{3} \mathrm{He}_{\text {tri }}$ in young groundwater samples containing tritium. The resulting ${ }^{3} \mathrm{He}_{\text {tri }}$ differs between models and so does the ${ }^{3} \mathrm{H}-{ }^{3} \mathrm{He}$ water age $\tau$ (Tolstikhin and Kamenskiy, 1969; Torgersen et al., 1979):

$$
\tau=\frac{1}{\lambda} \ln \left(1+\frac{{ }^{3} H e_{t r i}}{{ }^{3} H}\right)
$$

where $\lambda=0.05626 \mathrm{yr}^{-1}$ (Lucas and Unterweger, 2000). Depending on the choice of the gas exchange model, ${ }^{3} \mathrm{H}-{ }^{3} \mathrm{He}$ water ages differ by up to a factor of 2 (Fig. 5b). Shown are the water ages for all samples in which ${ }^{3} \mathrm{H}$ has been detected and ${ }^{3} \mathrm{He}_{\text {tri }}$ is significantly larger than zero. The water ages predicted by the PR-model appear unrealistically large. They suggest that around 1930 the tritium concentration at recharge $\left({ }^{3} \mathrm{H}_{\text {rech }}=\right.$ $\left.{ }^{3} \mathrm{H}_{\mathrm{m}}+{ }^{3} \mathrm{He}_{\mathrm{tri}}\right)$, i.e., at the bottom of the $30 \mathrm{~m}$ thick unsaturated zone, were up to $10 \mathrm{TU}$, which seems unrealistic. A consistency test of the ${ }^{3} \mathrm{H}-{ }^{3} \mathrm{He}$ water ages based on the comparison of ${ }^{3} \mathrm{H}_{\text {rech }}$ with the historic ${ }^{3} \mathrm{H}$ concentration at recharge (AeschbachHertig et al., 1998; Stute et al., 1997) is not practicable in the CT-aquifers because the ${ }^{3} \mathrm{H}$ at recharge is strongly affected by the transport through the unsaturated zone. Hence, only the inclusion of the $\mathrm{Ne}$ isotopes in the analysis provides an objective, i.e., data-based, criterion to identify the ${ }^{3} \mathrm{H}-{ }^{3} \mathrm{He}$ water ages predicted by the $\mathrm{CE}$-model to be more reliable than those predicted by the PR-model.

\subsubsection{Simplified procedures to estimate $\mathrm{He}$ atm}

In many studies the dating procedure outlined above is not applicable because measurements of heavy noble gases are not available. Ne can be used to estimate excess air even if the recharge temperature is only approximately known, because the equilibrium concentration $\mathrm{Ne}^{*}$ only weakly depends on temperature (Table 1). Usually (e.g., AeschbachHertig et al., 1998; Ekwurzel et al., 1994; Schlosser et al., 1989 ; Torgersen et al., 1979) the $\mathrm{Ne}$ excess $\left(\Delta \mathrm{Ne}=\mathrm{Ne}_{\mathrm{m}^{-}}\right.$ $\left.\mathrm{Ne}^{*}\right)$ has been used to calculate the atmospheric He excess from $\Delta \mathrm{He}=\Delta \mathrm{Ne} \cdot\left(\mathrm{z}_{\mathrm{He}} / \mathrm{z}_{\mathrm{Ne}}\right)$, .i.e., assuming unfractionated excess air (UA-model). However, if the excess air is fractionated, its $\mathrm{He} / \mathrm{Ne}$ ratio can be significantly lower than $z_{H e} / z_{N e}$ (Holocher et al., 2001), particularly in the case of the PR-model.

The equivalent application of the UA-model to the Ne data from young groundwater samples $\left({ }^{4} \mathrm{He}_{\text {ter }}<1.5 \cdot 10^{-7}\right.$ $\mathrm{cm}^{3} \mathrm{STPg}^{-1}$ ) of the CT aquifers, assuming the recharge temperature $T$ to correspond to the annual mean soil temperature of $\sim 32^{\circ} \mathrm{C}$ (CESBIO/ORSTOM/CNES.HAPEX SAHEL Information System, 1996), results in predicted concentrations of ${ }^{3} \mathrm{He}_{\mathrm{atm}}$ that are 0.7 to $3.2 \%$ larger than those predicted by the CE-model using the concentrations of all noble gases and the ${ }^{20} \mathrm{Ne} /{ }^{22} \mathrm{Ne}$ ratio (Fig. 5a, Table 3). This demonstrates that the estimation of ${ }^{3} \mathrm{He}_{\mathrm{atm}}$ based on $\Delta \mathrm{Ne}$ and the assumption of unfractionated excess air provides a reasonable approximation if the gas excess is not strongly fractionated and fractionation is not of PR-model type. However, the information contained in the Ne concentration is not sufficient to test the validity of the assumption that fractionation is small or to distinguish between the different models. 
It is possible to estimate the effect of fractionation on ${ }^{4} \mathrm{He}_{\mathrm{atm}}$ and ${ }^{3} \mathrm{He}_{\mathrm{atm}}$ if the ${ }^{20} \mathrm{Ne} /{ }^{22} \mathrm{Ne}$ ratio is considered in addition to the elemental $\mathrm{Ne}$ concentration. Using these two constraints and assuming that recharge temperature is approximately known, the model Eqn. 1 and 2 can be solved for the parameters $A_{p r}$ and $F_{p r}$ or $A_{c e}$ and $F_{c e}$, respectively. With the derived model parameters, ${ }^{4} \mathrm{He}_{\mathrm{atm}}$ and ${ }^{3} \mathrm{He}_{\mathrm{atm}}$ can be calculated from Eqn. 1 and 2, respectively. Equivalently, Noble can be employed to fit the parameters $A_{p r}$ and $F_{p r}$ or $A_{c e}$ and $F_{c e}$, respectively, based on the measured $\mathrm{Ne}$ concentration, the ${ }^{20} \mathrm{Ne} /{ }^{22} \mathrm{Ne}$ ratios and a prescribed recharge temperature.

Application of this method to the $\mathrm{Ne}$ concentrations and ${ }^{20} \mathrm{Ne} /{ }^{22} \mathrm{Ne}$ ratios from the $\mathrm{CT}$ aquifers provides ${ }^{3} \mathrm{He}_{\mathrm{atm}}$ and ${ }^{4} \mathrm{He}_{\mathrm{atm}}$ which are very similar for all three models (PR-, CEand UA-model). The reason is that the inverse fitting based only on $\mathrm{Ne}$ concentrations and the ${ }^{20} \mathrm{Ne} /{ }^{22} \mathrm{Ne}$ ratio suggests that fractionation is small. The deviation between the ${ }^{3} \mathrm{He}_{\text {atm }}$ predicted using the reduced data set and the best estimate of ${ }^{3} \mathrm{He}_{\mathrm{atm}}$ predicted using all available data ranges between $-3.9 \%$ and $3.2 \%$ for all young groundwater samples with ${ }^{4} \mathrm{He}_{\text {ter }}<1.5 \cdot 10^{-7} \mathrm{~cm}^{3} \mathrm{STPg}^{-1}$ (see Table 3). Although a clear decision between UA-, CE- and PR-model is impossible on the basis of $\mathrm{Ne}$ concentration and ${ }^{20} \mathrm{Ne} /{ }^{22} \mathrm{Ne}$ ratio, the range of possible ${ }^{3} \mathrm{He}_{\text {atm }}$ can be estimated and strong fractionation of PR-model type can be distinguished from fractionation according to the CE-model or from unfractionated excess air as in the UA-model (Table 3).

Compared to the PR-model, the He-Ne fractionation according to the CE-model is not very different from unfractionated excess air (UA-model). Hence for dating studies the distinction between the CE- and the UA-model is not as critical as the distinction between the CE-and the PR-model. Nevertheless, in the case of samples with very young age, for which the difference between total ${ }^{3} \mathrm{He}$ and ${ }^{3} \mathrm{He}_{\text {atm }}$ is small, and in the case of a large contribution of excess gas, the prediction of ${ }^{3} \mathrm{He}_{\text {tri }}$ and water age may differ significantly depending on whether CE- or UA-model is applied. Since the UA-model corresponds to the CE-model with $F_{c e}=0$, the distinction between CE- and UA-model essentially is the problem of determining the parameters $A_{c e}$ and $F_{c e}$ of the CE-model from a limited data set on noble gases and noble gas isotopes. The ${ }^{20} \mathrm{Ne} /{ }^{22} \mathrm{Ne}$ ratio is not suitable to determine whether $F_{c e}=0$ or not, because the solubilities of the $\mathrm{Ne}$ isotopes are very similar such that the ${ }^{20} \mathrm{Ne} /{ }^{22} \mathrm{Ne}$ ratio in atmospheric equilibrium is approximately the same as in the atmosphere. However, estimation of $A_{c e}$ and $F_{c e}$ could be based on the Ar concentration together with the $\mathrm{Ne}$ concentration and the ${ }^{20} \mathrm{Ne} /{ }^{22} \mathrm{Ne}$ ratio. The $\mathrm{Ne} / \mathrm{Ar}$ ratio in atmospheric equilibrium differs significantly from that in the atmosphere (Table 2) and Ar concentrations can be measured comparatively easy and are less dependent on recharge temperature than the concentrations of the heavy noble gases $\mathrm{Kr}$ and $\mathrm{Xe}$.

In case of the Niger data, the constraint by $\mathrm{Ne}$ and $\mathrm{Ar}$ concentrations together with the ${ }^{20} \mathrm{Ne} /{ }^{22} \mathrm{Ne}$ ratios is sufficient to rule out the UA- and PR-models, whereas the predictions according to the CE-model are compatible with the data from the young groundwater samples according to a $\chi^{2}$-test $\left(\mathrm{p}\left(\chi_{\text {set }}^{2}=29\right)>3 \%\right)$. Considering the groundwater samples individually, predictions according to the CE-model are consistent with the data of all samples $\left(\mathrm{p}\left(\chi^{2}\right)>1 \%\right.$ for all 27 samples) while the predictions of the PR- and the UA-model are acceptable only for 2 and 3 samples, respectively. Note that including the ${ }^{20} \mathrm{Ne} /{ }^{22} \mathrm{Ne}$ ratio is required to distinguish between the PR- and CE-model. Fitting based on Ne and Ar concentrations alone only allows rejection of the UA-model (Table 3).

The parameters $A_{c e}$ and $F_{c e}$ estimated from inverse fitting based on $\mathrm{Ne}$ and $\mathrm{Ar}$ concentrations and the ${ }^{20} \mathrm{Ne} /{ }^{22} \mathrm{Ne}$ ratio can be employed to determine the concentration of ${ }^{3} \mathrm{He}_{\text {atm }}$ and ${ }^{4} \mathrm{He}_{\mathrm{atm}}$. The ${ }^{3} \mathrm{He}_{\mathrm{atm}}$ concentrations agree within $\pm 0.2 \%$ with the reference value obtained from the concentrations of $\mathrm{Ne}, \mathrm{Ar}$, $\mathrm{Kr}, \mathrm{Xe}$ and the ${ }^{20} \mathrm{Ne} /{ }^{22} \mathrm{Ne}$ ratio (Table 3). In Figure 5a the predicted ${ }^{3} \mathrm{He}_{\text {atm }}$ (crosses) is compared to the predictions using the UA-model based only on $\mathrm{Ne}$ (triangles) and to the predictions using the CE- and the PR- models based on concentrations of $\mathrm{Ne}, \mathrm{Ar}, \mathrm{Kr}$ and $\mathrm{Xe}$ (solid and open circles, respectively).

The prediction of ${ }^{3} \mathrm{He}_{\text {atm }}$ based on the concentrations of $\mathrm{Ne}$, Ar and the ${ }^{20} \mathrm{Ne} /{ }^{22} \mathrm{Ne}$ ratio only weakly depends on $T$. For recharge temperatures between $30^{\circ} \mathrm{C}$ and $35^{\circ} \mathrm{C}{ }^{3} \mathrm{He}_{\text {atm }}$ deviates from the best value by less than $1 \%$ for the young groundwater samples (Table 3). The $\chi_{\text {set }}^{2}$ for the fits with $T=30^{\circ} \mathrm{C}$ and $T$ $=35^{\circ} \mathrm{C}$ are larger than for $T=32^{\circ} \mathrm{C}$, indicating that the latter is the most appropriate value for the recharge temperature, in agreement with the the soil temperature and the noble gas temperatures derived from all noble gas concentrations using the CE-model.

${ }^{3} \mathrm{H}-{ }^{3} \mathrm{He}$ water ages calculated from the ${ }^{3} \mathrm{He}_{\mathrm{atm}}$ and ${ }^{4} \mathrm{He}_{\mathrm{atm}}$ obtained from the simplified procedures discussed above agree well with the ${ }^{3} \mathrm{H}-{ }^{3} \mathrm{He}$ water ages derived from the entire data set using the CE-model (Fig. 5b). Water ages derived using the usual $\mathrm{He}$ correction based only on $\Delta \mathrm{Ne}$ are typically 1 to $2 \mathrm{yr}$ younger than the best estimates. This is particularly important in studies concerned with dating in very young groundwaters. In the samples 19 and $30{ }^{3} \mathrm{H}$ and ${ }^{3} \mathrm{He}_{\text {tri }}$ are very small, such that small uncertainties in ${ }^{3} \mathrm{He}_{\text {atm }}$ lead to large errors in the ${ }^{3} \mathrm{H}-{ }^{3} \mathrm{He}$ water age. Water ages based on $\mathrm{Ne}, \mathrm{Ar}$ and ${ }^{20} \mathrm{Ne} /{ }^{22} \mathrm{Ne}$ agree with the best estimates within error and in most cases the ${ }^{3} \mathrm{H}-{ }^{3} \mathrm{He}$ water ages deviate by less than $0.2 \mathrm{yr}$.

\section{CONCLUSIONS}

Concentrations of noble gas isotopes carry information on gas partitioning during groundwater recharge which might not be available from the elemental noble gas concentrations of $\mathrm{Ne}$, $\mathrm{Ar}, \mathrm{Kr}$, and $\mathrm{Xe}$. Specifically, in the CT-aquifers of Niger a decision between the PR- and the CE-model is impossible based only on the elemental concentrations. If however measurements of the ${ }^{20} \mathrm{Ne} /{ }^{22} \mathrm{Ne}$ ratio are included in the analysis, the PR-model has to be rejected according to a $\chi^{2}$-test and only the CE-model is compatible with the entire data set. This finding is also confirmed by the ${ }^{36} \mathrm{Ar} /{ }^{40} \mathrm{Ar}$ ratio, which is incompatible with the PR-model. Thus the concentrations of noble gas isotopes allow a decision between PR- and CE-model which influences the prediction of recharge temperature, initial amount of excess air, and fractionation and hence affects the interpretation of the data with respect to paleoclimatic conditions.

The distinction between PR-, CE- and UA-model is also important in ${ }^{3} \mathrm{H}-{ }^{3} \mathrm{He}$ dating. In groundwaters with fractionated 
gas excess, ${ }^{3} \mathrm{He}_{\text {atm }}$ required to calculate ${ }^{3} \mathrm{He}_{\text {tri }}$ strongly depends on the fractionation model employed. Commonly the excess gas contributing to ${ }^{3} \mathrm{He}_{\text {atm }}$ is estimated from $\Delta \mathrm{Ne}$ assuming unfractionated excess air (UA-model). The effect of fractionation can only be assessed by including additional experimental information. Combination of the $\mathrm{Ne}$ concentration with the ${ }^{20} \mathrm{Ne} /{ }^{22} \mathrm{Ne}$ ratio allows estimation of the range of possible values of ${ }^{3} \mathrm{He}_{\mathrm{atm}}$, thus providing the range of possible water ages. However, this procedure is not suitable to distinguish between PR-, CE- and UA-model if fractionation is small, i.e., if the ${ }^{20} \mathrm{Ne} /{ }^{22} \mathrm{Ne}$ is between the value in the atmosphere and the value at atmospheric equilibrium. Extending the data set consisting of $\mathrm{Ne}$ concentration and ${ }^{20} \mathrm{Ne} /{ }^{22} \mathrm{Ne}$ ratio by the concentration of Ar enables a rigorous distinction between models and a reliable estimation of ${ }^{3} \mathrm{He}_{\mathrm{atm}}$ and ${ }^{4} \mathrm{He}_{\text {atm }}$ and of ${ }^{3} \mathrm{H}-{ }^{3} \mathrm{He}$ water ages.

Acknowledgments—Associate editor: B. Marty

\section{REFERENCES}

Aeschbach-Hertig W., Beyerle U., Holocher J., Peeters F., and Kipfer R. (2001). Excess air in groundwater as a potential indicator of past environmental changes. International Conference on the Study of Environmental Change Using Isotope Techniques. 34-36.

Aeschbach-Hertig W., Peeters F., Beyerle U., and Kipfer R. (1999) Interpretation of dissolved atmospheric noble gases in natural waters. Water Res. Res. 35(9), 2779-2792.

Aeschbach-Hertig W., Peeters F., Beyerle U., and Kipfer R. (2000) Palaeotemperature reconstruction from noble gases in ground water taking into account equilibration with entrapped air. Nature 405, $1040-1044$

Aeschbach-Hertig W., Schlosser P., Stute M., Simpson H. J., Ludin A., and Clark J. F. (1998) A ${ }^{3} \mathrm{H} /{ }^{3} \mathrm{He}$ study of ground water flow in a fractured bedrock aquifer. Ground Water 36(4), 661-670.

Andrews J. N., Fontes J.-C., Aranyossy J.-F., Dodo A., Edmunds W. M., Joseph A., and Travi Y. (1994) The evolution of alkaline groundwaters in the continental intercalaire aquifer of the Irhazer Plain, Niger. Water Res. Res. 30(1), 45-61.

Andrews J. N. and Lee D. J. (1979) Inert gases in groundwater from the Bunter Sandstone of England as indicators of age and palaeoclimatic trends. J. Hydrol. 41, 233-252.

Ballentine C. J. and Hall C. M. (1999) Determining paleotemperature and other variables by using an error-weighted, nonlinear inversion of noble gas concentrations in water. Geochim. Cosmochim. Acta 63(16), 2315-2336.

Ballentine C. J., Peeters F., Aeschbach-Hertig W., Beyerle U., Holocher J., and Kipfer R. (1999) Inverting noble gas concentrations in natural gas: Determination of gas/groundwater interaction and a test for conceptual models of gas transport and emplacement. Am. Geophys. Union, Fall Meeting, F1168.

Benson B. B. and Krause D. (1980) Isotopic fractionation of helium during solution: A probe for the liquid state. J. Sol. Chem. 9(12), 895-909.

Beyerle U., Aeschbach-Hertig W., Imboden D. M., Baur H., Graf T., and Kipfer R. (2000a) A mass spectrometric system for the analysis of noble gases and tritium from water samples. Env. Sci. Technol. 34(10), 2042-2050.

Beyerle U., Aeschbach-Hertig W., Peeters F., and Kipfer R. (2000b). Accumulation rates of radiogenic noble gases and noble gas temperatures deduced from the Great Artesian Basin, Australia. Beyond 2000-New Frontiers in Isotope Geoscience 21.

Beyerle U., Purtschert R., Aeschbach-Hertig W., Imboden D. M., Loosli H. H., Wieler R., and Kipfer R. (1998) Climate and groundwater recharge during the last glaciation in an ice-covered region. Science 282, 731-734.
Beyerle U., Rueedi J., Leuenberger M., Aeschbach-Hertig W., Peeters F., Kipfer R., and Dodo A. (in press) Evidence for periods of wetter and cooler climate in the Sahel between 6 and $40 \mathrm{kyr}$ BP derived from groundwater. Geophys. Res. Lett.

Brennwald, M. S., Peeters, F., Beyerle, U., Rüedi, J., Hofer, M., and Kipfer, R. (2001) InEGS 26th General Assembly; Society, E. G., Ed.; EGS: Nice, p HSA6.

CESBIO/ORSTOM/CNES.HAPEX SAHEL Information System. 1996 http://www.ird.fr/hapex/.

Clever H. L. (1979) Krypton, xenon and radon-gas solubilities. In Solubility data series (ed. I. U. o. P. a. A. Chemistry),Vol. 2, pp. 357. Pergamon Press.

Ekwurzel B., Schlosser P., Smethie W. M., Plummer L. N., Busenberg E., Michel R. L., Weppernig R., and Stute M. (1994) Dating of shallow groundwater: Comparison of the transient tracers ${ }^{3} \mathrm{H} /{ }^{3} \mathrm{He}$, chlorofluorocarbons, and ${ }^{85} \mathrm{Kr}$. Water Res. Res. 30(6), 1693-1708.

Heaton T. H. E. and Vogel J. C. (1981) "Excess air" in groundwater. $J$. Hydrol. 50, 201-216.

Holocher J., Matta V., Aeschbach-Hertig W., Beyerle U., Hofer M., Peeters F., and Kipfer R. (2001) Noble gas and major element constraints on the water dynamics in an alpine floodplain. Ground Water 39, 841-852.

Jähne B., Heinz G., and Dietrich W. (1987) Measurement of the diffusion coefficients of sparingly soluble gases in water. J. Geophys. Res. 92(C10), 10767-10776.

Kipfer R., Aeschbach-Hertig W., Baur H., Hofer M., Imboden D. M., and Signer P. (1994) Injection of mantle type helium into Lake Van (Turkey): The clue for quantifying deep water renewal. Earth Planet. Sci. Lett. 125, 357-370.

Kipfer R., Aeschbach-Hertig W., Hofer M., Hohmann R., Imboden D. M., Baur H., Golubev V., and Klerkx J. (1996) Bottomwater formation due to hydrothermal activity in Frolikha Bay, Lake Baikal, eastern Siberia. Geochim. Cosmochim. Acta 60(6), 961971.

Lucas L. L. and Unterweger M. P. (2000) Comprehensive review and critical evaluation of the half-life of Tritium. J. Res. Natl. Inst. Stand. Tech. 105(4), 541-549.

Mazor E. (1972) Paleotemperatures and other hydrological parameters deduced from gases dissolved in groundwaters, Jordan Rift Valley, Israel. Geochim. Cosmochim. Acta 36, 1321-1336.

Ozima M. and Podosek F. A. (1983) Noble gas geochemistry. Cambridge Univ. Press.

Schlosser P., Stute M., Dörr C., Sonntag C., and Münnich K. O. (1988) Tritium $/{ }^{3} \mathrm{He}$-dating of shallow groundwater. Earth Planet. Sci. Lett. 89, 353-362.

Schlosser P., Stute M., Sonntag C., and Münnich K. O. (1989) Tritiogenic ${ }^{3} \mathrm{He}$ in shallow groundwater. Earth Planet. Sci. Lett. 94, 245-256.

Solomon, D. K. (2000) ${ }^{4} \mathrm{He}$ in groundwater In Environmental tracers in subsurface hydrology (eds. P. Cook and A. L. Herczeg) pp. 529. Kluwer Academic Publishers.

Stute M., Deák J., Révész K., Böhlke J. K., Deseö É., Weppernig R., and Schlosser P. (1997) Tritium $/{ }^{3} \mathrm{He}$ dating of river infiltration: An example from the Danube in the Szigetkös area, Hungary. Ground Water 35(5), 905-911.

Stute M., Forster M., Frischkorn H., Serejo A., Clark J. F., Schlosser P., Broecker W. S., and Bonani G. (1995) Cooling of tropical Brazil $\left(5^{\circ} \mathrm{C}\right)$ during the Last Glacial Maximum. Science 269, $379-383$.

Stute M. and Schlosser P. (1993) Principles and applications of the noble gas paleothermometer. In Climate Change in Continental Isotopic Records (ed. P. K. Swart, K. C. Lohmann, J. McKenzie, and S. Savin) Vol. 78, pp. 89-100. American Geophysical Union.

Stute M. and Talma A. S. (1998) Glacial temperatures and moisture transport regimes reconstructed from noble gases and delta ${ }^{18} \mathrm{O}$, Stampriet aquifer, Namibia. Isotope techniques in the study of environmental change 307-318.

Tolstikhin I. N. and Kamenskiy I. L. (1969) Determination of groundwater ages by the T- ${ }^{3} \mathrm{He}$ Method. Geochem. Int. 6, 810-811. 
Torgersen T., Clarke W. B., and Jenkins W. J. (1979) The tritium/ helium-3 method in hydrology. Iso. Hydrol. 1978, 917-930.

Torgersen T., Kennedy B. M., Hiyagon H., Chiou K. Y., Reynolds J. H., and Clark W. B. (1989) Argon accumulation and the crustal degassing flux of ${ }^{40} \mathrm{Ar}$ in the Great Artesian Basin, Australia. Earth Planet. Sci. Lett. 92, 43-56.

Weiss R. F. (1970) The solubility of nitrogen, oxygen and argon in water and seawater. Deep-Sea Res. 17, 721-735.
Weiss R. F. (1971) Solubility of helium and neon in water and seawater. J. Chem. Eng. Data 16(2), 235-241.

Weiss R. F. and Kyser T. K. (1978) Solubility of krypton in water and seawater. J. Chem. Eng. Data 23(1), 69-72.

Weyhenmeyer C. E., Burns S. J., Waber H. N., Aeschbach-Hertig W., Kipfer R., Loosli H. H., and Matter A. (2000) Cool glacial temperatures and changes in moisture source recorded in Oman groundwaters. Science 287(5454), 842-845. 